\title{
As denominações das abóboras no Hunsrückisch sul-americano ${ }^{1}$
}

\author{
Fernando Hélio Tavares de Barros ${ }^{2}$ \\ Universidade de Bremen (UB), Bremen, Alemanha
}

Resumo: Provenientes do Novo Mundo, as abóboras se popularizaram em vários continentes após a descoberta da América. No Brasil, as cucúrbitas possuem, em sua maioria, nomenclatura de matriz luso-brasileira. É com esse patrimônio denominativo que os imigrantes alemães se depararam ao chegarem ao Brasil no início do século 19. Este trabalho apresenta dados advindos da aplicação da pergunta 106 do questionário semântico-lexical do Projeto Atlas Linguístico-Contatual das Minorias Alemãs na Bacia do Prata - Hunsrückisch (ALMA-H). A pergunta tinha por objetivo coletar as denominações das abóboras no repertório lexical do Hunsrückisch, língua de imigração alemã falada na Bacia do Prata e no além de suas fronteiras. Guiado pela Dialetologia pluridimensional e relacional (RADTKE; THUN, 1996), - ALMA-H documentou 34 denominações de cucúrbitas. As designações coletadas revelam não só os reflexos do contato linguístico, mas também uma série de neologismos surgidos da necessidade do colono alemão de nomear a natureza da terra que o recebeu.

Palavras-chave: Dialetologia Pluridimensional e Relacional; Hunsrückisch; Estudo do Léxico; Denominações das Abóboras.

Title: The names of the pumpkins in South American Hunsrückisch

Abstract: Originating from the New World, pumpkins had become popular on several continents after the discovery of America. In Brazil, most varieties of cucurbits derive from LusoBrazilian nomenclature. German immigrants encountered this diverse denominative heritage when they arrived in Brazil at the beginning of the 19th century. Our work presents data generated from the 106th question of the semantic-lexical questionnaire of the Project Linguistic Atlas of German Minorities in the La Plata Basin - Hunsrückisch (ALMA-H). The purpose of this question was to collect the different names of pumpkins used in the Hunsrückisch lexical repertoire, a German immigration language spoken in the La Plata Basin and beyond. Guided by the Pluridimensional and Relational Dialectology (RADTKE and THUN, 1996), the ALMA-H documented 34 denominations of cucurbits. The collected designations reveal not only the influences of linguistic contact, but also a series of neologisms arising from the German settler's need to name nature on the earth that received him.

Keywords: Pluridimensional and Relational Dialectology; Hunsrückisch; Study of the Lexicon; Pumpkin Names.

\footnotetext{
${ }^{1}$ Este trabalho analisa dados que foram apresentados na Tese de Doutorado de Tavares de Barros (2019) e foi financiado por bolsa CNPq/DAAD.

2 Doutor em Linguística (Universidade de Bremen). Orcid: https://orcid.org/0000-0002-9893-2775 Email: tavaresd@uni-bremen.de.
} 


\section{Introdução}

É dia 24 de julho de 1859, e, motivado pela saudade, Friedrich Konrad resolve escrever uma carta aos seus pais e demais familiares que ficaram na pequena Niederkumb, vilarejo situado no Hunsrück (Renânia-Palatinado, Alemanha). O imigrante conta as dificuldades que encontrou ao chegar ao Rio Grande do Sul, mas também as maravilhas e as singularidades da vida na colônia onde os imigrantes de fala alemã se assentaram. Entre as peculiaridades está uma planta que, conforme conta o autor, se costuma plantar entre o milho. Ela se espalha por toda a superfície e seu fruto de tão pesado, às vezes, precisa ser carregado por três pessoas. "É chamada de Bobern", segue o autor, e sua serventia vai desde o uso culinário como também para alimentar os animais. Seu gosto se assemelha ao da cenoura (ver ENGELMANN, 2004, p. 300).

Friedrich Konrad tenta descrever a abóbora para os seus da maneira mais próxima à realidade da sua terra natal. Ao contrário dos imigrantes alemães, a abóbora no hábito alimentar dos seus vizinhos luso-brasileiros ${ }^{3}$ remonta, em parte, à cultura gastronômica trazida das terras banhadas pelo Tejo, o Douro e o Mondego. Num dos documentos mais valiosos da língua portuguesa, o livro de receitas da Infanta Dona Maria de Portugal [15381577] (ver MANUPPELLA; ARNAUT, 1967), a abóbora é apresentada como uma iguaria popular entre os portugueses.

Levadas com as navegações ibéricas, sendo boa parte originárias das Américas Central e Andina (LORENZI; MATOS, 2002), as abóboras se popularizaram na Península Ibérica e, em particular, no hábito alimentar dos portugueses de diferentes classes sociais. ${ }^{4}$ Seu uso na gastronomia lusitana ainda é muito presente (CASCUDO, 1966). Não só grande parte da diversidade de abóboras, mas também a expressiva parcela de seu patrimônio denominativo popular veio se estabelecer no português do Brasil, evidentemente por meio das correntes imigratórias de portugueses.

Sabe-se também que entre os povos originários, em particular entre os guaranis, certas cucúrbitas faziam parte do cotidiano alimentar, nomeadamente, as chamadas andaí ou curapépé (GATTI, 1985). Cabe considerar, igualmente que, desde que chegaram à Europa, as abóboras deixaram de ser uma novidade para os ibéricos e que, portanto, a nomenclatura criada pelos portugueses para as abóboras e trazida à América subsidiou, dentro do patrimônio denominativo estabelecido no Brasil, uma sobreposição das denominações lusas sob as autóctones.

\footnotetext{
${ }^{3}$ Cabe lembrar que o assentamento dos imigrantes alemães no Rio Grande do Sul, especificamente da região do vale do Sinos até o vale do Pardo e Pardinho, ocorre em terras situadas à região de colonização portuguesa (dos campos de Viamão até às margens do Sinos, Jacuí, Taquari, Caí e Pardo). Essa região de matriz-cultural lusa é conhecida na historiografia pelos seus núcleos de povoamento (de 1700 em diante) de imigrantes ilhéus (dos Açores e da Madeira), de portugueses vindos de Portugal continental e de luso-brasileiros vindos da capitania de São Paulo e Santa Catarina (ver VOLKWEIS, 2011; ROCCA, 2009).

${ }^{4}$ Como se pode ver na passagem da carta de Dona Joana Baptista - escrita entre 1619-1621 - há o pedido ao destinatário por piedade de uma freira que, segundo a autora, foi injustiçada por uma denúncia infundada: "des the de iso por esmola e dous arasteis de cõfeitos de rosa q são bõs pera saúde e mea dúzia de talhadas d abobra porq ela não comia senão cousas frias por ser mui doēte" [itálico meu]. Fonte: Projeto Post Scriptum Uni. de Lisboa.
} 
Além disso, é bem possível que grande parte das cucúrbitas trazidas pelos lusitanos não existiam na América portuguesa. As abóboras sempre se fizeram presentes na cultura alimentar. Usada tanto na doçaria ${ }^{5}$ quanto como opção de guarnição para o arroz e o feijão, a famosa 'mistura' na culinária luso-brasileira.

Conforme Körber-Grohne (1994), a primeira vez que a abóbora foi descrita de maneira detalhada na Europa central foi na obra de Langethal de 1845, em seu livro sobre a cultura de plantas agricultáveis. Contudo, nesse tempo, o plantio dessas cucúrbitas se dava nas regiões de temperaturas mais temperadas da Alemanha.

O objetivo deste trabalho é apresentar as denominações das abóboras advindas da pergunta 106 do questionário semântico-lexical do ALMA-H. Para tanto, em um primeiro momento se faz uma breve exposição do Projeto ALMA-H, em particular de seus aspectos metodológicos. Logo após, apresentam-se todas as formas lexicais para as abóboras, seguidas da análise dos principais nomes para as duas principais variedades de cucúrbitas (a Cucurbita maxima e a Cucurbita moschata), conforme seus aspectos etimológicos, contatuais, diarreferenciais e diatópicos. A análise é seguida das considerações finais.

\section{O Projeto ALMA-H}

O Atlas Linguístico das Minorias Alemãs na Bacia do Prata - Hunsrückisch (ALMA-H) é um projeto conjunto da Universidade Federal do Rio Grande do Sul (UFRGS) com a Universidade de Kiel (CAU). Seu objetivo foi, desde então, proporcionar uma macroanálise do Hunsrückisch falado na Bacia do Prata. Essa variedade de alemão é, correntemente, descrita na literatura como uma koiné de base francônica-renana e moselana à qual, no processo de nivelamento, se agregaram elementos do português e de outras variedades dialetais do alemão. ${ }^{6}$

A formação dessa koiné ocorreu na velha região colonial alemã - doravante Alte Kolonie (pt. colônia velha) - localizada entre os vales do Rio dos Sinos, Caí, Taquari, Pardo e Pardinho situados no Rio Grande do Sul. A difusão dessa variedade dialetal alemã se deu da Alte Kolonie para as novas colônias situadas na região das Missões, no noroeste gaúcho, e de lá para os alhures da fronteira com a Argentina e o Paraguai e também para Santa Catarina, sudoeste e oeste do Paraná, em zonas do Brasil central (Centro-Oeste) e da Amazônia meridional.

Sob coordenação de Cléo V. Altenhofen (UFRGS, Porto Alegre) e Harald Thun (CAU, Kiel), o ALMA-H foi financiado pela Alexander von Humbold-Stiftung durante os anos de 2008 a 2012. O respectivo atlas possui uma rede de pontos de 41 localidades espalhadas por uma

\footnotetext{
${ }^{5}$ Como o caso da Cucurbita ficifolia. Com diferentes nomes - caiota, chila, gila-caiota -, no Rio Grande do Sul ela é conhecida por abóbora-gila. É popular em toda a zona de (i)migração portuguesa e luso-brasileira, sendo o município de Bom Jesus da Serra - RS, no alto dos Campos de Cima da Serra, popular pela festa nacional da gila. Da gila se faz o doce cabelo-de-anjo.

6 "Hrs. ist der Oberbegriff für eine überregionale Varietät des Deutschen in Rio Grande do Sul/Südbrasilien, die ein Dialektkontinuum darstellt, dessen sprachliche Konstituition auf eine rhein-/moselfränkische Basis zurückgeht und eine Vielfalt sprachkontaktbedingter Elemente anderer deutscher Dialekte sowie insbesondere solche des Ptg. einschließt" (KOCH, 1974, p. 96).
} 
região que vai desde a RS01 (São Leopoldo e Novo Hamburgo), os pontos mais antigos de povoamento, até aos pontos MT01 e MT02 na Amazônia mato-grossense, e PY04 no centroleste paraguaio. A relação de todas as localidades pode ser acessada no site do Projeto ALMA-H (https://www.ufrgs.br/projalma/rede-de-pontos/). Aprovado pelo Comitê de Ética em Pesquisa (CEP) da UFRGS (parecer n. 1.083.590), o corpus recolhido para esse atlas linguístico é composto de 128 entrevistas, que juntas somam em torno de 800 horas de áudio gravado. Para além das entrevistas, o ALMA-H dispõe de um rico banco de etnotextos e iconografias coletadas em campo. ${ }^{7}$

A metodologia empregada no ALMA-H é a da Dialetologia pluridimensional e relacional (RADTKE; THUN, 1996), vertente moderna da Dialetologia que conflui os interesses da Dialetologia tradicional com os da Sociolinguística variacionista, tentando sanar as lacunas de ambas as disciplinas do estudo da variação linguística. A combinação das duas perspectivas forma um espaço tridimensional que pode ser visualizado no esquema ilustrado na fig. 1.

Figura 1 - Modelo estrutural da Dialetologia pluridimensional e relacional

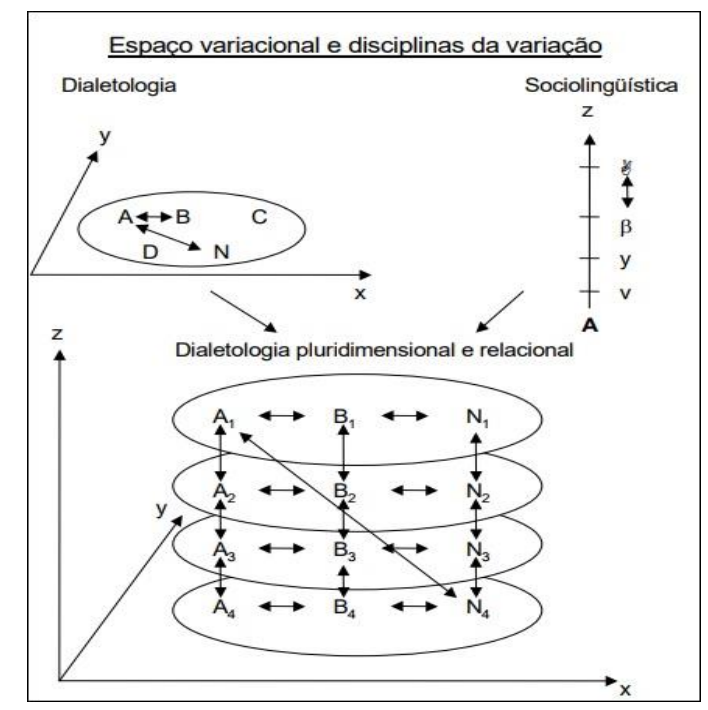

Fonte: Thun (1998, p. 705).

O nome se deve às diversas dimensões e aos diversos parâmetros existentes nessa abordagem, e à possibilidade de relacioná-los na análise do fenômeno linguístico. ${ }^{8}$ Essas dimensões (doravante dim.) aumentam as perspectivas do estudo da variação linguística, uma vez que se consideram na análise a idade dos falantes (diageracional), o sexo (diassexual), a localidade (diatópica), a religião (diarreligiosa), os comentários metalinguísticos (diarreferencial), entre outras.

Através dessa metodologia, já foram realizados vários atlas linguísticos, entre eles, o Atlas linguístico Diatópico y Diastrático del Uruguay - ADDU (ver THUN et al., 1989) e o Atlas Lingüístico Guarani-románico - ALGR (ver THUN et al., 2009), e outrossim diversas teses de

\footnotetext{
${ }^{7}$ Informações baseadas em Altenhofen (2016).

${ }^{8}$ As minúcias desse método são tratadas nos trabalhos de Radtke e Thun (1996), Thun (1998; 2010).
} 
doutorado e dissertações de mestrado, principalmente, as orientadas por Harald Thun e Cléo V. Altenhofen e que podem ser acessadas no portal do Proj. ALMA-H. ${ }^{9}$

Os informantes entrevistados para o ALMA-H são, em sua maioria, bilíngues português-hunsriqueano. Na Argentina e no Paraguai, os informantes, na maioria dos casos, são trilíngues português/espanhol/hunsriqueano. Entre os mais jovens, ocorre de haver informantes bilíngues espanhol/hunsriqueano. No Paraguai, boa parte dos informantes são tetralíngues português/espanhol/guarani/hunsriqueano. No ponto PY04 (Moseldorf, Paso Tuyá - Paraguai), encontraram-se informantes que, além das quatro línguas mencionadas, falavam inglês e o baixo alemão - Plattdeutsch - falado pelos vizinhos menonitas. Os entrevistados pertencem a quatro grupos diferentes. Os grupos estão divididos em duas gerações, sendo Gl o grupo dos jovens e GII o dos mais velhos. Além disso, eles estão repartidos em duas classes sociais distintas: $\mathrm{Ca}$ a de alta escolaridade e a $\mathrm{Cb}$ de baixa escolaridade. Na fig. 2, é possível ver a distribuição dos grupos na cruz que, no mapa, representa cada ponto de inquérito.

Figura 2 - Esquema de Cruz com perfil dos falantes entrevistados pelo ALMA-H

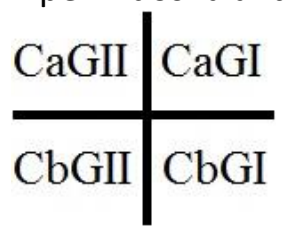

Fonte: Projeto ALMA-H.

Os informantes do ALMA-H nasceram na localidade ou residiam ali, por pelo menos $3 / 4$ de suas vidas, sendo que, nesses casos, respeitando a obrigatoriedade de ter residido no lugar nos últimos 5 anos. Os critérios estabelecidos na seleção de informantes estão representados no quadro seguinte:

Quadro 1 - Descrição dos grupos de informantes

\begin{tabular}{|c|c|}
\hline CaGII & $\begin{array}{l}\text { Um homem e uma mulher acima de } 55 \text { anos. Nascidos na localidade, ou que viveram } 3 / 4 \text { da vida } \\
\text { nesse lugar (obrigatoriamente os últimos } 5 \text { anos) e com escolaridade nível superior. }\end{array}$ \\
\hline CaGI & $\begin{array}{l}\text { Um jovem e uma jovem de } 18 \text { a } 36 \text { anos. Nascidos na localidade, ou que viveram } 3 / 4 \text { da vida na } \\
\text { localidade (obrigatoriamente os últimos } 5 \text { anos) e com escolaridade nível superior. }\end{array}$ \\
\hline CbGII & $\begin{array}{l}\text { Um homem e uma mulher acima de } 55 \text { anos. Nascidos na localidade, ou que viveram } 3 / 4 \text { da vida na } \\
\text { localidade (obrigatoriamente os últimos } 5 \text { anos). Com escolaridade básica (analfabeto até } 20 \text { grau } \\
\text { incompleto) e ocupação profissional agricultor ou empregado que não exija o uso da escrita. }\end{array}$ \\
\hline CbGI & $\begin{array}{l}\text { Um jovem e uma jovem de } 18 \text { a } 36 \text { anos. Nascidos na localidade, ou que viveram } 3 / 4 \text { da vida na } \\
\text { localidade (obrigatoriamente os últimos } 5 \text { anos). Com escolaridade básica (analfabeto até } 29 \text { grau } \\
\text { incompleto) e ocupação profissional agricultor ou empregado que não exija o uso da escrita. }\end{array}$ \\
\hline
\end{tabular}

Fonte: Projeto ALMA-H.

\footnotetext{
${ }^{9}$ Na plataforma on-line da UFRGS. Link: https://www.ufrgs.br/projalma/bibliografia/bibliografia/. Acesso em: 22 out. 2020.
} 
O inquérito utilizado pelo ALMA-H possui 6 partes principais. A parte correspondente ao questionário semântico-lexical (Clex) é dividida em 15 temáticas e contém no total 283 perguntas. A maioria das perguntas dispõe de variantes lexicais usadas, por parte do entrevistador, como sugestões aos informantes. Isso, no caso de não serem ditas de maneira espontânea.

O método de entrevista da Dialetologia pluridimensional e relacional aplica, principalmente, no que tange ao questionário semântico-lexical, o procedimento dos três passos: perguntar, insistir e sugerir.

Ao contrário da vertente tradicional da Dialetologia, o modelo pluridimensional e relacional não se contenta com a primeira resposta dos informantes, perspectiva que é conhecida na literatura como coleta de dados "sem retoque" (fr. sans retouche). O referido tipo de coleta é um procedimento da Dialetologia monodimensional iniciado por Jules Gilliéron e seu colega Edmond Edmont no Atlas linguistique de la France (ALF, 1902-1910). Conforme Thun (2000), a visão tradicional se contenta apenas com uma foto do fenômeno linguístico. Isso seria, na perspectiva de Gilliéron, um único clique que produziria uma foto fiel da língua e distante de manipulações.

Os graus de uso e de conhecimento das variantes recolhidas são dados preciosos, principalmente, para identificar processos de mudança e inovação linguísticas. Nas palavras de Thun (2010), a aplicação dos três passos, além de levar em conta as funções da memória humana, também fornece informações relevantes a respeito da mudança linguística, em particular, no que tange a dois aspectos: o do gradual desaparecimento de formas e o da generalização de novas formas.

Por essa razão, a Dialetologia pluridimensional e relacional amplia o zoom da documentação de uma forma lexical, pois se interessa em registrar o seu conhecimento ativo (os dados avindos de respostas espontâneas, ou seja, a primeira resposta ou após insistência), o conhecimento passivo (os dados referentes às sugestões aceitas) e, quando ocorre, também o seu desconhecimento.

\section{Os dados gerados pela pergunta 106 do quest. semântico-lexical do ALMA-H}

Com o propósito de documentar as denominações das abóboras no repertório lexical hunsriqueano, aplicou-se a pergunta 106 através da seguinte formulação: “Como se chama aquele fruto, que se espalha pelo chão, produz frutos de formas diferente e deles se pode fazer saladas, doces e cozidos?". ${ }^{10}$

As variantes registradas nos 41 pontos de inquérito do ALMA-H reuniram formas de quatro línguas diferentes: alemão, português (pt.), espanhol (es.) e guarani (gn.). A identificação das formas se deu por meio da literatura consultada. As lexias identificadas como próprias do alemão local foram reunidas e organizadas no quadro 2. Já no quadro 3,

\footnotetext{
${ }^{10}$ Cabe salientar que, apesar de ser a mais frequente, nem sempre os entrevistadores aplicaram a questão por meio dessa formulação. Conforme o inquiridor, a pergunta era formulada de maneira distinta, contudo sempre de aplicação semasiológica.
} 
estão as variantes classificadas como próprias dos repertórios do português, do espanhol e do guarani dos informantes. Nos referidos quadros se encontra, para além das variantes, uma coluna para a frequência $(\Sigma)$ e outras para informar as ocorrências por ponto de inquérito, conforme os quatro grupos de informantes (CaGll, $\mathrm{CaGl}, \mathrm{CbGII}$ e CbGI). Como o presente estudo não se foca na variação fonética das variantes, as lexias que possuem uma correspondente no Hochdeutsch foram grafadas conforme a grafia da língua standard alemã. Esse procedimento leva em conta o tipo (ale. Typ) da lexia, elevando o foco no aspecto lexical e deixando o fonético, por enquanto, num segundo plano. Cabe ainda salientar que os lusismos germanizados foram considerados, neste trabalho, como elementos integrados e são tratados, portanto, como elementos pertencentes ao alemão falado no local.

Quadro 2 - As denominações de cucúrbitas recolhidas pelo ALMA-H

\begin{tabular}{|c|c|c|c|c|c|}
\hline Variantes & $\Sigma$ & CaGII & CaGI & CbGII & CbGI \\
\hline Bop & 01 & & RS23 & & \\
\hline Bower & 119 & $\begin{array}{l}\text { RS01, RS02, RS04, } \\
\text { RS05, RS06, RS07, } \\
\text { RS08, RS09, RS10, } \\
\text { RS11, RS12, RS13, } \\
\text { RS15, RS16, RS18, } \\
\text { RS19, RS20, RS21, } \\
\text { RS22, RS23, SC05, } \\
\text { SC06, PR02, PR03, } \\
\text { MT01, MT02, AR02 }\end{array}$ & $\begin{array}{l}\text { RS01, RS02, RS04, RS05, } \\
\text { RS06, RS07, RS08, RS09, } \\
\text { RS10, RS11, RS12, RS13, } \\
\text { RS14, RS16, RS18, RS19, } \\
\text { RS20, RS21, RS22, RS23, } \\
\text { SC02, SC03, SC05, SC06, } \\
\text { PR02, PR03, MT02, } \\
\text { AR02, PY02 }\end{array}$ & $\begin{array}{l}\text { RS02, RS04, RS05, } \\
\text { RS06, RS07, RS08, } \\
\text { RS09, RS12, RS13, } \\
\text { RS14, RS15, RS16, } \\
\text { RS18, RS20, RS21, } \\
\text { RS22, RS23, SC01, } \\
\text { SC02, SC03, SC04, } \\
\text { SC05, SC06, PR02, } \\
\text { PR03, MT01, MT02, } \\
\text { AR01, AR02, AR03, } \\
\text { PY01, PY02, PY03, } \\
\text { PY04 }\end{array}$ & $\begin{array}{l}\text { RS02, RS04, RS06, } \\
\text { RS07, RS08, RS09, } \\
\text { RS10, RS11, RS12, } \\
\text { RS13, RS16, RS19, } \\
\text { RS20, RS21, RS22, } \\
\text { RS23, SC01, SC02, } \\
\text { SC03, SC04, SC05, } \\
\text { SC06, PR02, PR03, } \\
\text { AR01, AR02, PY02, } \\
\text { PY03, PY04 }\end{array}$ \\
\hline Bowermeninches & 01 & & SCO2 & & \\
\hline Flaschenkürbis & 01 & & & PY01 & \\
\hline Fütterbower & 01 & & & RS06 & \\
\hline Halsmorange & 01 & & & RS15 & \\
\hline Halskürbis & 02 & & & SC02 & SCO2 \\
\hline Halsbower & 110 & $\begin{array}{l}\text { RS02, RS04, } \\
\text { RS05, RS06, RS07, } \\
\text { RS08, RS10, RS11, } \\
\text { RS14, RS15, RS18, } \\
\text { RS19, RS20, RS22, } \\
\text { RS23, SC05, SC06, } \\
\text { PR03, MT01, MT02 }\end{array}$ & $\begin{array}{l}\text { RS02, RS04, RS05, RS06, } \\
\text { RS07, RS08, RS09, RS10, } \\
\text { RS11, RS12, RS13, RS14, } \\
\text { RS15, RS19, RS20, RS21, } \\
\text { RS22, RS23, SC02, SC03, } \\
\text { SC05, SC06, PR02, PR03, } \\
\text { MT02, AR02, PY02 }\end{array}$ & $\begin{array}{l}\text { RSO2, RS04, RS05, } \\
\text { RSO6, RS07, RS08, } \\
\text { RS10, RS11, RS12, } \\
\text { RS13, RS14, RS15, } \\
\text { RS18, RS19, RS20, } \\
\text { RS21, RS22, RS23, } \\
\text { SC02, SC03, SC04, } \\
\text { SC05, SC06, PR02, } \\
\text { PR03, MT01, MT02, } \\
\text { AR01, AR02, AR03, } \\
\text { PY01, PY02, PY03, } \\
\text { PY04 }\end{array}$ & $\begin{array}{l}\text { RS02, RS04, RS05, } \\
\text { RS06, RS07, RS08, } \\
\text { RS09, RS10, RS11, } \\
\text { RS13, RS14, RS15, } \\
\text { RS16, RS18, RS19, } \\
\text { RS20, RS21, RS22, } \\
\text { RS23, SC03, SC04, } \\
\text { SC05, SC06, PR02, } \\
\text { AR01, AR02, PY02, } \\
\text { PY03, PY04 }\end{array}$ \\
\hline Kochbower & 24 & $\begin{array}{l}\text { RS06, RS08, RS11, } \\
\text { RS22, PR03 }\end{array}$ & $\begin{array}{l}\text { RS10, RS11, } \\
\text { RS21, SC03 }\end{array}$ & $\begin{array}{l}\text { RS02, RS04, RS05, } \\
\text { RS06, } \\
\text { RS07, RS08, RS10, } \\
\text { RS11, } \\
\text { AR02, PY01 }\end{array}$ & $\begin{array}{l}\text { RS04, RS08, } \\
\text { RS11, PY03 }\end{array}$ \\
\hline Kürbis & 08 & $\mathrm{RS} 12, \mathrm{SC} 05$ & MT02 & $\begin{array}{l}\text { RS20, SC02, SC03, } \\
\text { PY01 }\end{array}$ & SCO2 \\
\hline Morange & 27 & $\begin{array}{l}\text { RS14, RS16, RS18, } \\
\text { RS19, RS21, RS23, } \\
\text { PR02 }\end{array}$ & $\begin{array}{l}\text { RS05, RS09, RS12, RS19, } \\
\text { RS21, SC05, SC06, PR02 }\end{array}$ & $\begin{array}{l}\text { RS04, RS13, RS14, } \\
\text { RS15, RS21, RS23, } \\
\text { SC05, PR03 }\end{array}$ & $\begin{array}{l}\text { RS12, RS14, SC06, } \\
\text { PR03 }\end{array}$ \\
\hline
\end{tabular}



Hunsrückisch sul-americano

\begin{tabular}{|llllll|}
\hline Morangeche & 02 & & SC06 & RS18 & \\
Saufenbower & 01 & RS22 & & & RS08 \\
Schwanzbower & 01 & & & RS07 & RS06 \\
Schweinbower & 06 & RS11, AR02, PY02 & RS11 & RS04 & \\
Stängebower & 01 & & & MT02 & \\
Sternbower & 01 & & & \\
Stockbower & 01 & AR02 & RS21 & RS07, RS11, AR02 \\
Riesenbower & 01 & PR03 & RS18 & \\
Rundbower & 01 & & RS09 & & \\
Saumelone & 05 & & & \\
\hline
\end{tabular}

Fonte: Projeto ALMA-H.

Quadro 3 - As variantes do português, espanhol e guarani

\begin{tabular}{|c|c|c|c|c|c|}
\hline Variante & $\Sigma$ & CaGII & CaGI & CbGII & CbGI \\
\hline abóbora (pt.) & 43 & $\begin{array}{l}\text { RS01, RS04, RS05, } \\
\text { RS07, RS08, RS11, } \\
\text { RS15, RS19, MT01 }\end{array}$ & $\begin{array}{lll}\text { RS08, } & \text { RS10, } & \text { RS11, } \\
\text { RS18, } & \text { RS19, } & \text { RS23, } \\
\text { SC02, } & & \\
\end{array}$ & $\begin{array}{l}\text { RS01, RS05, RS14, } \\
\text { RS16, RS18, RS19, } \\
\text { RS20, SC02, SC03, } \\
\text { PR02, PR03, MT01, } \\
\text { PY04 }\end{array}$ & 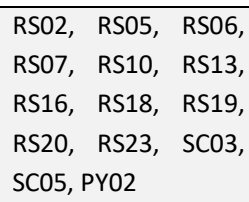 \\
\hline abobrinha (pt.) & 02 & RS07, MT01 & & & \\
\hline abóbora-menina (pt.) & 06 & RS05, RS08 & $\mathrm{sC} 02$ & RS05, RS19 & RS06 \\
\hline abóbora-de-pescoço (pt.) & 09 & RS08, RS19 & RS10 & $\begin{array}{l}\text { RS08, RS14, RS19, } \\
\text { SC02 }\end{array}$ & $\mathrm{RS} 18, \mathrm{SC05}$ \\
\hline andaí (gn.) & 01 & AR02 & & & \\
\hline bóbora (pt.) & 01 & & & AR02 & \\
\hline calabaza (es.) & 02 & & & AR02 & AR02 \\
\hline cabotiã (pt.) & 01 & & & МT02 & \\
\hline caxi (pt.) & 01 & & & МT02 & \\
\hline jerimum (pt.) & 01 & & & МT02 & \\
\hline moganga (pt.) & 01 & & & RS19 & \\
\hline moranga (pt.) & 97 & $\begin{array}{l}\text { RS01, RS04, RS05, } \\
\text { RS06, RS08, RS10, } \\
\text { RS13, RS14, RS15, } \\
\text { RS16, RS18, RS19, } \\
\text { RS20, RS21, RS22, } \\
\text { RS23, SC02, SC05, } \\
\text { SC06, PR02, } \\
\text { MT02 }\end{array}$ & 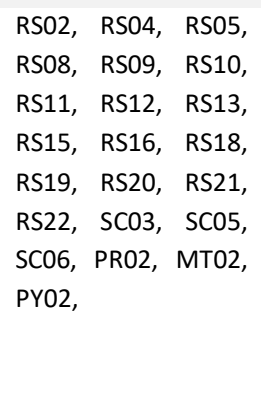 & 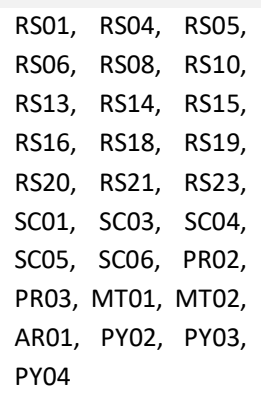 & 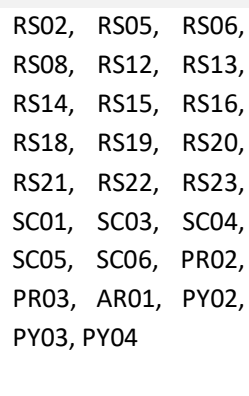 \\
\hline maranga (pt.) & 02 & & & SC01 & SC01 \\
\hline morango (pt.) & 01 & & & $\mathrm{SCO} 2$ & \\
\hline zapallo (es.) & 04 & AR02 & AR02 & AR01, AR02 & \\
\hline zapallo de cuello (es.) & 01 & & & & AR02 \\
\hline
\end{tabular}

Fonte: Projeto ALMA-H.

Esses dados geraram uma série cartográfica que, neste trabalho, é representada por três diferentes mapas. O primeiro (mapa 01, em anexo A) é pluridimensional em sua cartografia e mostra os dados separados por resposta espontânea e sugestão aceita. Os outros dois mapas (mapas 02 e 03) são polifórmicos e reúnem os resultados positivos (as 
respostas espontâneas e as sugestões aceitas) para quatro tipos de variantes ou grupos de variantes.

Em torno de 34 denominações foram encontradas nos dados do ALMA-H. Dois são os principais tipos de abóboras encontradas no Sul do Brasil, em particular, nas zonas de imigração alemã: a Cucurbita maxima (ver mapa 02, em anexo B) e a Cucurbita moschata. (ver mapa 03, em anexo C). Por essa razão, os entrevistadores do ALMA-H se restringiram a perguntar e sugerir apenas denominações para essas duas variedades. Denominações para outros tipos de cucúrbitas também foram documentadas nos dados do ALMA-H, contudo, como respostas espontâneas dos informantes.

As abóboras pertencem à família das cucurbitáceas. Trata-se, nas palavras de Lorenzi e Matos (2002), de uma "herbácea rasteira, anual, vigorosa, de ramos um tanto carnosos, podendo chegar até $10 \mathrm{~m}$. de comprimento" (LORENZI; MATOS, 2002, p. 194). Sua origem provável é nas Américas Central e Andina. Assim relatam Lorenzi e Matos (2002), Brücher (1977), Gotti (2007), Körber-Grohne (1994) e Pignatti (1982). Suas folhas são peltadas e revestidas de pelos ásperos. As flores são de coloração amarelo-alaranjada, de maneira geral solitárias, grandes e unissexuais (LORENZI; MATOS, 2002, p. 194).

Segundo Lorenzi e Matos (2002), a taxonomia das abóboras é tanto confusa quanto incerta, visto que elas já sofreram muita interferência do homem (idem, 2002, p. 194). De maneira geral, as abóboras se multiplicam apenas por sementes. Seus frutos assumem diferentes formas, conforme a variedade. Trata-se de uma planta cultivada em todo o mundo tropical, com foco na produção de frutos (idem, 2002, p. 194).

As denominações coletadas pelo ALMA-H foram consultadas na literatura lexicográfica existente. As descrições feitas das lexias constituem uma tentativa de poder reconstruir o passado de cada forma, facilitando assim chegar às conclusões sobre os empréstimos e conservações existentes no repertório lexical hunsriqueano. Primeiramente, se faz uma descrição dos termos mais comuns para a abóbora no contexto contatual do alemão como língua de imigração com o português e as demais línguas presentes na história topodinâmica dos hunsriqueanos na Bacia do Prata e seus alhures. Posteriormente, são descritas as formas lexicais identificadas para a variedade de abóbora C. maxima. Em seguida, as denominações para a C. moschata, e logo após os termos para outros tipos de cucúrbitas.

Na história do português, abóbora é quiçá a única palavra que denomina uma variedade enorme de cucurbitáceas (LEITE DE VASCONCELOS, 1936). Nos dados recolhidos do ALMA-H, o termo foi registrado em 43 ocorrências. Infelizmente, nem todos os entrevistadores perguntaram aos informantes se eles sabiam a palavra do português para tal recorte semântico-lexical.

Nos dados do ALMA-H, ainda foram registrados termos do guarani e do espanhol. Respectivamente, as formas andaí, zapallo e calabaza. A primeira é palavra do guarani e descrita por Sampaio (1986) como equivalente a abóbora no português. Já Peralta e Osuna (1950) a identificam como denominação para a C. moschata. Gatti (1985), no entanto, classifica andaí como nome para todas as variedades de C. pepo e C. moschata Duch. A 
segunda lexia - zapallo - é classificada por Chuchuy e Bouzo (1933) como um argentinismo que, aparentemente, tem raízes no quéchua (ver Dic. de la RAE, versão online). Já calabaza tem origem desconhecida, provavelmente, de origem pré-romana (COROMINAS, 1954). Não obstante, segundo Corominas (1954), hipóteses de etimólogos de que calabaza seja um moçarabismo não faltam.

A forma do hunsriqueano da Bacia do Prata mais popular é Bower ['bo:bə], com 119 ocorrências; foi documentada em todos os pontos de inquérito do ALMA-H (ver mapa 01 em anexo), onde se realizaram entrevistas. Em todos os pontos, pelo menos um grupo de informante usa Bower de forma espontânea. Bower é, certamente, o lusismo abóbra na sua forma germanizada e integrada no patrimônio lexical falado pelos hunsriqueanos, assim como elucida Altenhofen (1996). Na descrição desse processo feita por Altenhofen (1996), levanta-se como resultado o alçamento da vogal média baixa posterior acompanhado de seu alongamento: pt. [0] $\rightarrow$ Hsr. [o:]. Não é comum no Hunsrückisch, segundo Altenhofen (1996), a existência de proparoxítonas, o que justifica a adequação e a redução de matéria da forma pt. abób(o)ra $\rightarrow$ Hrs. Bower.

As raízes de Bower certamente remetem à forma mais reduzida do lusismo, ou seja, abóbra. Esse apontamento leva em consideração o fato de que abóbra é a forma regional do português rural falado no Sul do Brasil (OLIVEIRA, 2003; ALEXANDRE, 1994; TOKARSKI, 2004; FILIPAK, 2002) e em outras regiões brasileiras de matriz cultural luso-brasileira, como no Nordeste (NAVARRO, 1998). A variante abóbra tem, na realidade, suas origens na fala dialetal da Península lbérica ${ }^{11}$ e ainda faz parte do repertório do português rural falado no norte de Portugal (GONÇALVES, 1988, p. 57) e nos Açores (BARCELOS, 2008, p. 38; SARAMAGO et al., 2002, ALEAç carta 572).

Quadro 4-Comentários metalinguísticos para Bower

\begin{tabular}{|c|c|c|c|c|c|}
\hline Comentário & $\Sigma$ & CaGII & CaGI & CbGII & $\mathrm{CbGI}$ \\
\hline Bower é a que tem pescoço (Halsbower). & 6 & & $\begin{array}{l}\text { RS05, RS09, } \\
\text { PR02 }\end{array}$ & & $\begin{array}{l}\text { SC01, RS20, } \\
\text { PY04 }\end{array}$ \\
\hline Com Bower se faz doce / chimia (ale. Schmier). & 2 & RSO2 & RS13 & & \\
\hline Bower são as compridas. & 2 & PR02 & & & RS20 \\
\hline Bower é para todos os tipos (de abóbora). & 1 & & RSO2 & & \\
\hline Com Bower se faz salada. & 1 & RSO2 & & & \\
\hline Bower é diferente da Halsbower. & 1 & RS18 & & & \\
\hline Bower são as redondas. & 1 & & & & RS07 \\
\hline
\end{tabular}

Fonte: Projeto ALMA-H.

\footnotetext{
${ }^{11}$ Na concepção de Corominas (1954, p. 10), não restam dúvidas de que a forma abóbra é uma palavra autóctone da Península Ibérica. Corominas (1954) diz que abóbra possui raízes na flora galega e não no patrimônio lexical castelhano. Segundo o autor, abóbra "en realidad no es palabra castellana, como se ve por la o no diptongada, quizá la sacara la Acad. de las notas de Sarmiento sobre la Flora gallega, en las que Colmeiro halló esta forma" (COROMINAS, 1954, p. 10). Sua etimologia se baseia no hispano-latinismo apŏpĕris. Nas palavras do autor, as formas derivadas "bobra, abobrella, abobriella, bobrilla, bobrella se hallan en varias fuentes mozárabes de los SS. X-XIII, con referencia a Córdoba y al mozárabe oriental. La forma brueba de Abenalŷazzar prueba que la o tónica era breve" (COROMINAS, 1954, p. 10).
} 
Como mostra o quadro que reúne os comentários metalinguísticos para a forma Bower, existe uma multiplicidade de conteúdos semânticos para tal lexia. Não só as diferentes características físicas existentes nas cucúrbitas, mas também os diversos usos culinários são mencionados.

A variante Kürbis é a forma de fala alemã paralela a Bower dentro do repertório lexical do hunsriqueano sul-americano. Sua origem se remete à forma kurbiz do antigo alto alemão (ale. althochdeutsch), essa por sua vez tem raízes na forma lat. cucurbita do latim médio ou, mais provável, de curbita do latim vulgar (PFEIFER; BRAUN, 1993; SAUERHOFF, 2003; KLUGE, 1989). Consoante à descrição apresentada por Pfeifer e Braun (1993), as abóboras assim que chegaram da América herdaram, na língua alemã, a denominação que já era dada às cabaças (PFEIFER; BRAUN, 1993), em ale. Flaschenkürbis (bot. Langenaria siceraria). Assim também afirma Sauerhoff (2003). Cabe considerar nesse fato que as cabaças já eram conhecidas no Velho Mundo, no tempo do Império Romano, ou seja, bem antes da chegada das abóboras à Europa (ver BRÜCHER, 1977).

Nos dados do ALMA-H, a forma Kürbis possui 8 ocorrências. Comparado à Bower, a documentação de Kürbis é escassa. Ela foi sugerida apenas em 4 pontos de inquérito. Nesses 4 pontos, os entrevistados a desconheciam. Portanto, os 8 resultados positivos vieram como resposta espontânea. Seria importante que em projetos futuros essa lacuna fosse corrigida para que haja uma fotografia mais detalhada da vitalidade de Kürbis no alemão falado pelos hunsriqueanos. Isso resolveria, principalmente, a dúvida que existe sobre os graus e a vastidão do conhecimento passivo e do desconhecimento dessa lexia.

\section{As denominações para a Cucurbita maxima}

Conforme Lorenzi e Matos (2002), o gênero C. maxima é conhecido em português pelo nome moranga. A sua principal característica é a forma arredondada e achatada dos seus frutos. Pignatti (1982) a descreve como uma cucúrbita rastejante e trepadeira, de flores de pétalas em forma de sino e seus frutos achatados de casca e polpa amarelo-laranjadas e com sementes brancas. Sobre sua origem, Körber-Grohne (1994) afirma que, por meio dos descobrimentos arqueológicos, foi possível comprovar que os Andes peruanos representam a área de origem (ale. Ursprungsgebiet) da C. maxima. ${ }^{12}$

Para Brücher (1977), as últimas pesquisas feitas na Cucurbitologia (ale./fr. Cucurbitologie) mostram que a C. andreana, uma variedade de C. maxima, só é encontrada em sua forma selvagem numa zona geográfica que compreende grande parte do pampa argentino, sudeste da Bolívia e às margens do rio Uruguai. Brücher (1977) acredita que a C. andreana é mais castiça, e que, portanto, se constitui o tronco de origem da $C$. maxima.

\footnotetext{
12 "Bei den archäologischen Nachweisen in Amerika müssen wir zwei verschiedene Regionen unterscheiden (Abb. 73). Mexiko als Ursprungsgebit für den Gewöhlichen Kürbis (C.pepo), für den Moschuskürbis (C. moschata) und für C. mixta; Südamerika, vor allem Peru, für den Riesenkürbis (C. maxima)" (KÖRBER-GRONE, 1994, p. 310).
} 
Como já mencionado, moranga é a denominação do português brasileiro para a $C$. maxima (CASTELEIRO, 2001), em particular, no português falado no Sul do Brasil (FILIPAK, 2002; PORTO ALEGRE, 1980). Porto Alegre (1980) acredita que moranga tem raiz no "tupiguarani (morang ou porang, bonito, belo)" (idem, 1980, p. 136), contudo aparenta ser apenas uma especulação. Na língua portuguesa, a palavra morango, no masculino, se encontra dicionarizada para denominar o fruto do morangueiro (bot. Fragaria L.) desde a obra de Bluteau (1712-28). Machado (1977) descreve que a origem de morango vem "provavelmente do lat. morănīcu., do lat. mōru-, <<amora>>" (MACHADO, 1977, p. 163) e moranga "de morango" (idem, 1977, p. 163). Segundo Casteleiro (2002), no português europeu, moranga denomina "uma casta de uva com sabor semelhante ao do morango" (CASTELEIRO, 2001, p. 2524), mas moranga também "diz-se de uma variedade de cereja" (idem, 2001, p. 2524). Por conseguinte, a lexia parece ser atributo para várias espécies de plantas. Se o uso de moranga para denominar a $C$. maxima se deu pelo mesmo processo de empréstimo, cabe futuras investigações desvendar. $O$ que se sabe, até o momento, é que no português do Sul do Brasil ela é espontânea para nomear a C. maxima, no que concerne os dados do ALMA-H.

A forma moranga recebeu resultados positivos em 97 grupos de informantes do ALMA-H. Apenas os jovens de alta escolaridade dos pontos RS06 e AR02 desconhecem a palavra para denominar essa variedade de abóbora. Em 27 grupos de informantes, registraram-se resultados positivos para a variante Morange. Provavelmente, Morange é a forma germanizada de moranga. De Morange certamente originou-se Morangeche (SC06, CaGI; RS18, CbGII).

Quadro 5-comentários metalinguísticos para moranga

\begin{tabular}{|c|c|c|c|c|c|}
\hline Comentário & $\Sigma$ & CaGII & CaGI & CbGII & CbGI \\
\hline Moranga são as redondas. & 8 & $\begin{array}{l}\text { RS10, RS23, } \\
\text { MT01 }\end{array}$ & MT02 & RS18, AR01 & RS13, RS20 \\
\hline Moranga, assim se diz em brasileiro (português). & 3 & & & RS01, RS05 & RS02 \\
\hline Moranga é uma abóbora que chegou aqui nos últimos anos. & 2 & RS07 & & RS05 & \\
\hline Moranga é Kochbower no nosso alemão. & 2 & & & RS06, PY02 & \\
\hline Moranga são pequenas, redondas e duras. & 2 & & & RS18, AR01 & \\
\hline Moranga é aquela bem dura para cortar. & 2 & RS19 & & AR01 & \\
\hline Aqui para moranga se diz zapallo. & 2 & & & AR01, PY04 & \\
\hline Moranga, eu conheço essa palavra desde criança. & 1 & & & RS05 & \\
\hline Moranga é a que se compra no mercado. & 1 & RSO4 & & & \\
\hline Moranga serve para fazer saladas. & 1 & & & & RS13 \\
\hline Moranga é para fazer com carne. & 1 & & & PY02 & \\
\hline Moranga serve mais para fazer cozidos. & 1 & & RS09 & & \\
\hline Moranga não serve para fazer doce. & 1 & & & & PY03 \\
\hline Moranga é a palavra em Hochdeustch para Bower. & 1 & RS18 & & & \\
\hline Moranga é em alemão, já em português se diz morango. & 1 & & & & SC02 \\
\hline Moranga não tem pescoço. & 1 & МT02 & & & \\
\hline Moranga é de cor laranjada. & 1 & & RS09 & & \\
\hline
\end{tabular}

Fonte: Projeto ALMA-H. 
Os comentários dos informantes revelam, parcialmente, algumas características físicas da abóbora moranga: que elas são redondas (8 comentários), que algumas são pequenas e duras ( 2 comentários), que não possuem pescoço (1 comentário), são laranjadas ( 1 comentário) e que servem para fazer saladas, preparar com carne, fazer cozidos etc. 0 comentário "moranga é em alemão, já em português se diz morango" mostra indícios da integração dessa lexia no repertório lexical do hunsriqueano. Apesar dessa percepção e do registro de 27 ocorrências para Morange, a forma germanizada de moranga, há informantes que consideram moranga uma palavra que se diz somente no português (3 comentários).

A C. maxima é conhecida na língua alemã standard (ale. Hochdeutsch) pelos termos Winterkürbis, Riesenkürbis ou Halloweenkürbis. Nenhuma das formas foi registrada nas respostas dos informantes. Apenas o atributo modificador Riesen foi documentado na forma Riesenbower (PR03, CaGII). Tal atributo ocorre em vários fitônimos da língua alemã: Riesenbärenklau, Riesenblume, Riesenboretsch, Riesensteinbrech (SAUERHOFF, 2003, p. 758). Apesar de não haver comentários metalinguísticos (dados diarreferenciais) para a forma Riesenbower, pode-se imaginar que a referência ao tamanho da abóbora seja um indicador de identificação para o gênero C. maxima. Tal caso também é o da forma Rundbower (RS21, CbGII), com referência à sua forma arredondada em disparidade à fisionomia da C. moschata.

Para a C. máxima, também foi registrada a forma Kochbower (pt. "abóbora de cozinhar"), com 24 ocorrências nos dados do ALMA-H. A formação morfológica de Kochbower se dá pela composição do prefixo Koch (derivado do verbo ale. kochen $\rightarrow$ pt. cozinhar) com o lusismo germanizado Bower. O termo Koch, como atributo, é usual em construções morfológicas de fitônimos da língua alemã. Eis os casos das formas Kochapfel, Kochkraut, Kochsalat, Kochbirne (ver o Deutsches Wörterbuch de Jacob e Wilhelm Grimm [1854-1961]), entre outras. Segundo os comentários metalinguísticos dos informantes, Kochbower é a denominação do alemão para a variedade de abóbora conhecida em português como moranga (9 comentários).

Quadro 6 - Comentários metalinguísticos para a variante Kochbower

\begin{tabular}{|llllll|}
\hline \multicolumn{1}{|c}{ Comentário } & $\boldsymbol{\Sigma}$ & CaGII & CaGI & CbGII & CbGI \\
\hline Kochbower em português é moranga. & 09 & RS08 & RS10, SC03 & PY02, RS10, RS05, RS06, RS08 & RS08 \\
Kochbower é a que não tem pescoço. & 1 & & RS10 & & RS11 \\
Kochbower é a abóbora redonda. & 1 & & & Ren \\
\hline
\end{tabular}

Fonte: Projeto ALMA-H.

Nas respostas dos informantes, há mais ocorrências para moranga e suas variantes que para Kochbower. Contudo, se observa nos comentários dos informantes que moranga, e provavelmente sua variante Morange, não são as representantes mais alemãs. A identidade luso-brasileira de moranga é lembrada quando os informantes se lembram de Kochbower. Todas as 24 ocorrências de Kochbower foram no nível espontâneo. Lamentavelmente, não temos uma fotografia mais profunda de Kochbower, isto é, sua arealização tanto do conhecimento passivo quanto o seu desconhecimento. Tal situação se deve ao fato de que a 
forma não foi sistematicamente sugerida, o que acarretou lacunas em sua documentação. Por essa razão, a documentação de Kochbower se resume numa única fotografia, a de seu uso espontâneo. Apesar disso, pôde-se concluir que Kochbower possui menor documentação em nível espontâneo em comparação à sua concorrente, moranga. Isso possibilita interpretar que o neologismo Kochbower está sendo substituído pelo lusismo.

\section{As denominações para a Cucurbita moschata}

De acordo com Barbosa (195-), o gênero C. moschata possui uma diversidade de formas $^{13}$, sua configuração pode ser "dum cilindro recto ou curvo, ordinariamente entumescido na parte anterior, onde se encontram as sementes (...); outras vezes afecta uma forma esférica, ou a dum disco mais ou menos deprimido" (BARBOSA, 195-, p. 258). Como característica diferenciadora das outras variedades, a C. moschata possui uma pequena película de pelos em volta de suas folhas e de seus ramos (BRÜCHER, 1977). A origem geográfica, segundo Brücher (1977), certamente não foi na América do Sul. Até então somente se sabe que o centro da domesticação dessa cucúrbita foi na América Central (idem, 1977).

Conforme Barbieri et al. (2007), entre os nomes que denominam a C. moschata estão abóbora-menina e abóbora-de-pescoço. ${ }^{14}$ Ela representa uma "importante reserva de alimento para animais (como porcos e vacas), além de serem bastante utilizados no preparo de doces em calda e em pasta, além de pratos salgados (quibebe, sopas e cozidos)" (BARBIERI et al., 2007, p. 825-826).

A denominação abóbora-menina é corrente no português e está presente nos dois lados do atlântico. Em Portugal continental, no entanto, abóbora-menina é denominação para a C. maxima (CASTELEIRO, 2001; ROCHA, 1996). Assim também é nos Açores e na Madeira (BARCELOS, 2008; 2016). No Brasil, abóbora-menina é palavra usada no Paraná para uma "abóbora grande que se caracteriza por um pescoço comprido e encurvado" (FILIPAK, 2002, p. 30). De maneira semelhante, também descrevem Toniolo (1981) e Heiden et al. (2007). Essa descrição também ocorreu em um dos comentários dos informantes (SCO2, CaGI).

Quadro 7-comentários metalinguísticos para abóbora-menina

\begin{tabular}{|c|c|c|c|c|c|}
\hline Comentário & $\Sigma$ & CaGII & CaGl & CbGII & CbGI \\
\hline Abóbora-menina em alemão se diz Halsbower. & 5 & RS05, RS08 & SCO2 & RS05 & RS06 \\
\hline Abóbora-menina em alemão se diz Bowermeninches. & 1 & & SCO2 & & \\
\hline Abóbora-menina tem uma bunda pequena e o pescoço é fino e torto. & 1 & & SCO2 & & \\
\hline
\end{tabular}

\section{Fonte: Projeto ALMA-H.}

\footnotetext{
${ }^{13}$ Assim também diz Brücher (1977): “Die Früchte haben keine harten Schalen und variieren außerordentlich in ihren Formen" (BRÜCHER, 1977, p. 271).

${ }^{14}$ Barbieri et al. (2007) elucidam que, além desses dois nomes, a C. moschata é conhecida por moranga. No entanto, para os informantes do ALMA-H, a abóbora que possui um pescoço não leva esse nome (moranga).
} 
Nos dados do ALMA-H, a variante abóbora-menina teve seis ocorrências em cinco pontos de inquérito. No ponto SCO2 (CaGl), registrou-se a forma Bowermeninches. Um caso de calque linguístico (empréstimo via tradução do português para o Hunsrückisch) baseado em dois lusismos germanizados: Bower (do pt. abóbora) e meninches (do pt. menina). Pelo fato de abóbora-menina não ter sido sugerida pela maioria dos entrevistadores, suas ocorrências apareceram apenas como respostas espontâneas.

Cinco grupos de informantes comentaram que abóbora-menina é termo correlato para Halsbower. Aparentemente, a forma Halsbower é um decalque de abóbora-depescoço. ${ }^{15}$ Essa última é corrente no português falado no Sul do Brasil (HEIDEN et al., 2007, p. 27) e nos dados do ALMA-H abóbora-de-pescoço foi documentada em sete pontos de inquérito com nove ocorrências no total. No caso de Halsbower, a sua composição morfológica se dá pela junção do germanismo $\mathrm{Hals}^{16}$ (pt. pescoço) com o lusismo germanizado Bower (do pt. abóbora). Como se pode ver no quadro a seguir, cinco comentários de informantes afirmam que Halsbower é denominação hunsriqueana paralela ao lusismo abóbora-de-pescoço.

Quadro 8-comentários metalinguísticos para Halsbower

\begin{tabular}{|c|c|c|c|c|c|}
\hline Comentário & $\Sigma$ & CaGII & CaGI & CbGII & CbGI \\
\hline $\begin{array}{l}\text { Halsbower serve para fazer doce / chimia (ale. } \\
\text { Schmier). }\end{array}$ & 14 & $\begin{array}{l}\text { RS07, RS18, } \\
\text { Мт02 }\end{array}$ & $\begin{array}{l}\text { RS06, RS11, } \\
\text { RS22 }\end{array}$ & $\begin{array}{l}\text { RS02, RS06, } \\
\text { RS10, PY04 }\end{array}$ & $\begin{array}{l}\text { RS06, RS18, } \\
\text { PY02, PY03 }\end{array}$ \\
\hline Halsbower é a abóbora-menina (em português). & 5 & RS05, RS08 & & RS05, RS19 & RS06 \\
\hline Halsbower é a abóbora-de-pescoço (em português). & 5 & RS08, RS19 & & RS14, RS19 & RS18 \\
\hline Halsbower serve para alimentar os porcos. & 3 & & RSO6 & RS13, PY04 & \\
\hline Halsbower é a abóbora (em português). & 2 & & & PY04 & PY02 \\
\hline Halsbower são aquelas compridas. & 2 & & & & $\mathrm{RS} 02, \mathrm{RS} 20$ \\
\hline $\begin{array}{l}\text { Halsbower possui uma parte comprida e outra } \\
\text { redonda. }\end{array}$ & 1 & & & & PY02 \\
\hline $\begin{array}{l}\text { Halsbower dá para fazer salada quando ainda é } \\
\text { pequena. }\end{array}$ & 1 & & RS11 & & \\
\hline
\end{tabular}

Fonte: Projeto ALMA-H.

Foram documentadas 110 ocorrências para Halsbower. Em alguns pontos, ela aparece como sugestão aceita. No caso do ponto PR02 CbGl, se deve à insistência fraca por parte do entrevistador, ou seja, o intervalo entre perguntar e sugerir foi insuficiente para registrar mais formas espontâneas. Essa lacuna metodológica se junta a outra: a ausência da aplicação da forma Halsbower no passo da sugestão. Contudo, ambas as lacunas não impediram uma documentação densa dessa lexia, o que permitiu concluir que tal

\footnotetext{
${ }^{15}$ Esse tipo de construção nominal com a preposição de é comum em fitônimos do português: abóbora-decarneiro, alface-de-cabeça (ROCHA, 1996, p. 134).

${ }^{16}$ Como atestam alguns dicionários, a forma Hals é usada na língua alemã como atributo formador de fitônimos (nomes de plantas). Eis o caso de Halskraut - bot. Asperula cynanchica (Wörterbuch der luxemburgischen Mundart, 1906, versão online), Halswurz - bot. campanula trachelium (Deutsches Wörterbuch von Jacok Grimm und Wilhelm Grimm, 1854-1961, versão online), entre outros.
} 
neologismo se difundiu das colônias velhas até as localidades mais distantes ao norte (PY04, MT01, MT02) da rede de pontos do ALMA-H.

Assim como mostram os comentários, tanto para Bower quanto para Halsbower, as abóboras são usadas na culinária dos colonos alemães para diversos fins. Segundo os informantes do ALMA-H, delas fazem cozidos, saladas e doces (pt. RS chimia). Curiosamente, Staub (1983) diz que, na localidade de São Martinho - RS, o uso da abóbora se restringe apenas como alimento para os animais e que "os moradores de SM, de modo algum poderiam imaginar-se comendo o fruto da aboboreira" (STAUB, 1983, p. 101). Na Renânia, a abóbora é igualmente utilizada somente para a alimentação dos animais, assim como elucida Müller (1933, p. 1757). Já em 1845, Langethal descrevia o uso da abóbora na Alemanha principalmente para a nutrição dos porcos (ver KÖRBER-GROHNE, 1994). No entanto, em consonância com o que escreveu o imigrante Friedrich Konrad aos seus parentes, o uso da abóbora na gastronomia de matriz cultural luso-brasileira foi integrado nos hábitos alimentares do colono alemão, provavelmente, já nas primeiras décadas da imigração.

Para a variedade de $C$. moschata, foram proferidas pelos informantes as variantes Halskürbis, Flaschenkürbis, Halsmorange e o hispanismo zapallo de cuello. Apenas para a forma Flaschenkürbis (trad. pt. abóbora-garrafa) foi recolhido um comentário: "Flaschenkürbis é outra palavra para Halsbower". Como já mencionado, na língua alemã Flaschenkürbis é denominação para a cabaça (bot. Lagenaria siceraria) (SAUERHOFF, 2003). Por essa razão, Flaschenkürbis como termo para a C. moschata seria um caso de neologismo semântico no alemão falado pelos hunsriqueanos, visto que a forma é velha, mas o conteúdo semântico é inovador.

\section{Outras denominações recolhidas}

Entre os dados gerados pela pergunta 106 (ALMA-H), foram documentadas denominações que não são para as cucúrbitas $C$. maxima e $C$. moschata. Em certos casos, trata-se de nomes de origem e motivação desconhecidas.

A forma caxi foi registrada no ponto MT02 (CbGII). De acordo com Madeira et al. (2013), caxi é uma das denominações para a espécie Lagenaria, também conhecida por abóbora-d'água, abóbora-marimba, "nas regiões central e Sul de Minas Gerais; caxi e caxixi, no Norte de MG; e porongo, chuchu-porongo e catuto, no Rio Grande do Sul" (MADEIRA et al., 2013, p. 27). Caxi também foi documentada por Miranda (2015), em seu estudo sobre o léxico do Vale do Jequitinhonha (MG).

No ponto MT02 (CbGII), registrou-se a variante cabotiã. Segundo Amaro et al. (2018), esse tipo de abóbora é resultado "do cruzamento entre linhagens selecionadas de moranga (Cucurbita maxima Duch.), empregadas como genitores femininos e linhagens de abóbora (C. moschata Duch.), como genitores masculinos" (AMARO et al., 2018, p. 11). Desenvolvida no Japão e trazida para o Brasil, essa cucúrbita também é conhecida por cabotiá ou abóbora japonesa. Em outras línguas, ela é chamada de Ebisu, Delica, Hoka ou Hokkaido (PESSARAKI, 
2016). A forma cabotiá é, aparentemente, a forma lusitanizada da palavra japonesa kabocha. O nome é supostamente uma referência ao país Camboja, visto que, em 1541, marinheiros portugueses a teriam trazido do Camboja para o Japão. ${ }^{17}$

Assim como cabotiã e caxi, a forma jerimum foi dita pelos informantes do grupo CbGII do ponto MT02. Borba (2002) classifica jerimum como um regionalismo nordestino para designar a abóbora, igualmente faz Navarro (1998). Os dicionários regionais do português brasileiro mencionam jerimum no português da Paraíba (ALMEIDA, 1979; CLEROT, 1959), no Ceará (CABRAL, 1972; SERAINE, 1958) e no Pernambuco (PEREIRA DA COSTA, 1937). Para Pereira da Costa (1937), o termo "gerimum ou gerimu, é corruptela do vocábulo tupi jurumú" (PEREIRA DA COSTA, 1937, p. 371).

No entanto, jerimum é também palavra regional no português rural do Alto Minho (PEREIRA, 1970), do Trás-os-Montes e Alto Douro - norte de Portugal - para uma "grande abóbora amarela" (DIAS et al. 2005, p. 151), ou simplesmente "abóbora" (PIRES CABRAL, 2013, p. 679). Como esse tupinismo se integrou ao português rural do norte lusitano é uma questão sem resposta. Isso suscita uma nova etimologia para a lexia, a de que jerimum seja um velho galicismo integrado no português rural europeu e transportado, posteriormente, para o Brasil. Percorrendo o mesmo caminho que o galicismo fr. chouchou $\rightarrow$ pt. chuchu (bot. Sechium edule). No francês falado no Caribe se diz giraumon (jironmon, jiromon, giromon) para as abóboras. Assim é na ilha de Marie Galante (BARBOTIN, 1995) ${ }^{18}$ e no restante do Arquipélago de Guadalupe (LUDWIG et al., 1990; POULLET et al., 1984).

Com apenas uma ocorrência (RS19, CbGII), moganga foi outra variante dita pelos informantes. A origem de moganga é desconhecida. Se é o caso de variação fonética de moranga, ou o contrário, seria uma hipótese a ser considerada. De etimologia obscura, moganga não é apenas nome de uma variedade de abóbora, mas também sinônimo de "momice, trejeito ou conjunto de caretas, de esgares. (...) carícia ou série de gestos ternurentos" (CASTELEIRO, 2001, p. 2506). Sua forma masculina - mogango - também aparece na literatura como nome de abóbora. Borba (2002) descreve mogango como uma "variedade de abóbora de casca dura" (2002, p. 1052). Em Portugal, mogango é sinônimo de abóbora na região de Monsanto - no falar das Beiras (BARROS, 2010), no interior de Marvão (Alentejo) e seus arredores (SIMÃO, 2016) e de maneira geral no português do Alentejo (BARROS; GUERREIRO, 2005). É nas terras alentejanas que se faz a tradicional sopa de feijão com mogango. Nos Açores, mogango é, do mesmo modo, "certa espécie de abóbora (Cucurbita pepo); o m.q. moganga e bogango" (BARCELOS, 2008, p. 369). Na ilha da Madeira, se registra apenas a moganga como "variedade de abóbora (Cucurbita spp.), grande e muito apreciada na Madeira" (BARCELOS, 2016, p. 301).

No Brasil, mogango é vocábulo no português gaúcho e, do mesmo modo, nome para uma espécie de abóbora (BOSSLE, 2003; ROMAGUERA CORRÊA et al., 1964; OLIVEIRA, 2003).

\footnotetext{
17 “La kabocha que l’on utilise aujourd'hui s'est développée au Japon. Elle y aurait été importée par des marins portugais en 1541 du Cambodge, d'où son nom: 'kanbojia', transformé en 'kabocha”. Fonte: L'Express. Kabocha, la courge japonaise qui change de la butternut.

18 "Sorte de citrouille (Cucurbita). Ti bwen jiromon bon adan on soup: Un peu de giromon va bien dans la soupe" (BARBOTIN, 1995, p. 113).
} 
Romaguera Corrêa et al. (1964), contudo, ressaltam que não se deve confundir "com abóbora moganga, que é diferente" (idem, 1964, p. 310).

No repertório hunsriqueano, coletou-se, outrossim, a forma Saumelone ['sarnmelõnə]. O termo Melone existe na língua alemã desde o séc. 15 por meio de um empréstimo do it. mellone, melone (PFEIFER; BRAUN, 1993). ${ }^{19}$ Entre os diferentes nomes que essa lexia compõe na língua alemã (Wassermelone, Honigmelone, Zuckermelone etc.), na literatura consultada, Saumelone não foi encontrada. É possível que se trata de um caso de calque linguístico do lusismo melancia-de-porco. ${ }^{20}$

Nos dados analisados, apareceram ainda outras denominações de origem desconhecida relacionadas ao uso ou a características físicas das abóboras. Eis os casos de Stängelbower, Bowerschmier, Fütterbower, Schweinbower, Schwanzbower, Saufenbower, Sternbower, Stockbower. Elas são, aparentemente, neologismos próprios do Hunsrückisch platino. Contudo, é tarefa de investigações futuras revelarem maiores informações. No caso de Bowerschmier, há uma dúvida se o informante se referia ao doce (pt. RS chimia) feito da cucúrbita ou ao tipo de abóbora. A incerteza se embasa no fato de que no Hunsrückisch a construção dos nomes é, às vezes, irregular. Veja-se o caso de Bowermeninches.

\section{Considerações finais}

São sempre vastos e árduos os desafios para a Geolinguística documentar um campo lexical tão complexo e minucioso como o repertório denominativo das abóboras. Obviamente que, para um atlas linguístico, o trabalho de coletar dados satisfatórios do conteúdo semântico e do status de todas as variantes se torna exaustivo e nem sempre realizável. Por essa razão, como vimos neste estudo, a aplicação dos três passos do método da Dialetologia pluridimensional e relacional possibilita aumentar a densidade dos dados e suprir vazios.

De toda forma, apesar das lacunas, os resultados que o ALMA-H recolheu possibilitam novos caminhos no estudo do léxico do Hunsrückisch e do léxico do português falado no Sul do Brasil. Eles constituem uma base sólida para futuros estudos não só da Germanística, como também da Lusitanística brasileira, além de abrirem as portas para disciplinas como a História e a Antropologia se atentarem aos aportes que a pesquisa dialetológica pode oferecer.

\section{Referências}

ALEXANDRE, F. Dicionário da ilha: Falar \& Falares da ilha de Santa Catarina. Florianópolis: Cobra Coralina, 1994.

ALMEIDA, H. de. Dicionário popular paraibano. João Pessoa: Ed. UFPB, 1979.

\footnotetext{
19 "Der Name der kürbisartigen, saftigen Frucht ist eine Entlehnung (15. Jh.) von gleichbed. Ital. Mellone, melone zunächst in das süddt. Sprachgebiet" (PFEIFER; BRAUN, 1993, p. 859).

20 "melancia-de-porco, cujos frutos são usados para fazer doce ou então são dados como alimento para os porcos" (BARBIERI et al., 2007, p. 827).
} 
ALTENHOFEN, C. V. Hunsrückisch in Rio Grande do Sul. Ein Beitrag zur Beschreibung einer deutschbrasilianischen Dialektvarietät im Kontakt mit dem Portugiesischen. Stuttgart: Steiner, 1996.

ALTENHOFEN, C. V. Standard und Substandard bei den Hunsrückern in Brasilien: Variation und Dachsprachenwechsel des Deutschen im Kontakt mit dem Portugiesichen. In: LENZ, A. N. (Hg.). German Abroad: Perspektiven der Variationlinguistik, Sprachkontakt und Mehrsprachigkeitsforschung. Gottingen: Vienna University Press, 2016. p. 103-129. https://doi.org/10.14220/9783737005975.103

AMARO, G. B. et al. Desempenho de híbridos de abóbora japonesa no sistema orgânico. Brasília: Embrapa, 2018.

BARBIERI, R. L. et al. Resgate e conservação de variedades crioulas de cucurbitáceas do Sul do Brasil. Rev. Brasileira de Agroecologia (Online), v. 2, p. 824-827, 2007.

BARBOSA, J. C. A horta: tratado das hortaliças e outras plantas hortenses. 3. ed. Porto: Livr. Chardron de Lélo e Irmão, 195-.

BARBOTIN, M. Dictionnaire du créole de Marie-Galante. Hamburg: Buske, 1995.

BARCELOS, J. de. Dicionário de Falares dos Açores. Coimbra: Almedina, 2008.

BARCELOS, J. Dicionário de Falares do Arquipélago da Madeira. Funchal: SPGRAM, 2016.

BARROS, V. F.; GUERREIRO; L. M. Dicionário de Falares do Alentejo. Porto: Campos das Letras, 2005.

BARROS, V. F. Dicionário de Falares das Beiras. Lisboa: Âncora Ed., 2010.

BLUTEAU, R. Vocabulario Portuguez e Latino. 1712-1728. Disponível em: http://clp.dlc.ua.pt/DIClweb/LerFicha.asp?Edicao=1\&Posicao=2207573. Acesso em: 06 mai. 2020.

BORBA, F. S. Dicionário de usos do Português do Brasil. 1. ed. São Paulo: Ed. Ática, 2002.

BOSSLE, J. B. A. Dicionário gaúcho brasileiro. Porto Alegre: Artes e Ofícios, 2003.

BRÜCHER, H. Tropische Nutzpflanzen: Ursprung, Evolution und Domestikation. Berlin/Heidelberg: Springer-Verlag, 1977. https://doi.org/10.1007/978-3-662-13237-1

CABRAL, T. Dicionário de têrmos e expressões populares. Fortaleza: UFC, 1972.

Carta de soror Dona Joana Baptista, freira, para destinatário desconhecido - [1619-1621]. Projeto Post Scriptum. Disponível em: http://ps.clul.ul.pt. Acesso em: 30 ago. 2020

CASCUDO, L. da C. Abóbora e Jirimum. Rev. de Etnografia. Porto, vol. 6, Tomo 2, Impr. portuguesa, p. 307-312, 1966.

CASTELEIRO, J. M. (Cord.). Dicionário da Língua Portuguesa Contemporânea. Lisboa: Academia das Ciências de Lisboa; Editorial Verbo, 2001.

CHUCHUY, C.; BOUZO, L. H. de. Nuevo Diccionario de Americanismos / dir. G. Haensch y R. Werner. Tomo II: Nuevo Diccionario de Argentinismos. Santafé de Bogotá: Inst. Caro y Cuervo, 1993.

CLEROT, L. F. R. Vocabulário de Têrmos Populares e Gíria da Paraíba: estudo de Glotologia e Semântica Paraibana. 1. ed. Rio de Janeiro: Oficinas de Gráfica Riachuelo Editora, 1959. 
COROMINAS, J. Diccionario Crítico Etimológico de la Lengua Castellana. Vol. I A-C. Berna: Editorial Francke, 1954.

Deutsches Wörterbuch von Jacob und Wilhelm Grimm. 16 Bde. in 32 Teilbänden. Leipzig 1854-1961. Quellenverzeichnis Leipzig 1971. versão online. Disponível em: http://woerterbuchnetz.de/cgi-bin/WBNetz/wbgui_py?sigle=DWB. Acesso em: 10 abr. 2020.

DIAS, A. et al. Dicionário de Trasmontanismos. Chaves: Associação Rotary Club, 2005.

ENGELMANN, E. G. (Org.). A saga dos alemães - do Hunsrück para Santa Maria do Mundo Novo. Igrejinha: E. G. Engelmann, 2004.

FILIPAK, F. Dicionário sociolinguístico paranaense. Curitiba: Imprensa Oficial, 2002.

GATTI, C. Enciclopedia Guarani - Castellano de ciencias naturales. Asunción: Artes Nuevo, 1985.

GILLIÉRON, J.; EDMONT, E. Atlas Linguistique de la France. Paris: Champion, 1902-10.

GONÇALVES, G. A. M. O Falar do Minho. Liv. Sousa e Almeida: Porto, 1988.

GOTTI, M. G. Grande Enciclopedia illustrata della Gastronomia. Nuova ed. a cura dell'Università degli studi di scienze gastronomiche. Milano: Mondadori DOC, 2007.

HEIDEN, G. et al. Chave para a identificação das espécies de abóboras (Cucurbita, Cucurbitaceae) cultivadas no Brasil. Pelotas: Embrapa, 2007.

KLUGE, F. Etymologisches Wörterbuch der deutschen Sprache. Berlin: De Gruyter, 1989. https://doi.org/10.1515/9783110845037

$\mathrm{KOCH}$, W. Gegenwärtiger Stand der deutschen Sprache im brasilianischen Gliedstaat Rio Grande do Sul. In: ENGEL, U.; VOGEL, I. (org.) Deutsch in der Begegnung mit anderen Sprachen. Beiträge zur Soziologie der Sprachen. Editado por H. Kloss. Mannheim, Institut für deutsche Sprache, Tübingen: Narr, 1974. p. 79-117.

KÖRBER-GROHNE, U. Nutzpflanzen in Deutschland. Stuttgart: Konrad Theiss, 1994.

LEITE DE VASCONCELOS, J. Etnografia portuguesa. vol. 02. Lisboa: Impr. Nacional de Lisboa, 1936.

L'Express. Kabocha, la courge japonaise qui change de la butternut. Disponível em: https://www.lexpress.fr/styles/saveurs/kabocha-la-courge-japonaise-qui-change-de-labutternut 2049850.html. Acesso em: 05 abr. 2020.

LORENZI, H.; MATOS, F. J. de A. Plantas medicinais no Brasil: nativas e exóticas cultivadas. Nova Odessa-SP: Inst. Plantarum, 2002.

LUDWIG, R. et al. Dictionnaire créole français (Guadeloupe). Paris: Servedit, 1990.

MACHADO, J. P. Dicionário etimológico da língua portuguesa. 3. ed. Lisboa: Horizonte, 1977. MADEIRA, N. et al. Manual de produção de hortaliças tradicionais. Brasília: Embrapa, 2013.

MANUPPELLA, G.; ARNAUT, S. D. O "Livro de Cozinha" da Infanta D. Maria de Portugal. 1. ed. integral do Códice Português I. E. 33 da Biblioteca Nac. de Nápoles. Coimbra: Universidade (Acta Universitatis Conimbrigensis), 1967. 
MIRANDA, L. S. O léxico de remanescentes de comunidades garimpeiras do Alto Jequitinhonha - MG. 2015. 128 f. Tese (Doutorado em Linguística) - PPG em Estudos Linguísticos, UFMG, Belo Horizonte, 2015.

MÜLLER, J. Rheinisches Wörterbuch. Band 4, K- kalt. Berlin/ Bonn: Fritz Klopp, 1933.

NAVARRO, F. Assim falava Lampião: 2500 palavras e expressões nordestinas. São Paulo: Est. Liberdade, 1998.

OLIVEIRA, A. J. de. Dicionário gaúcho: termos, expressões, adágios, ditados e outras barbaridades. 2. ed. Porto Alegre: AGE, 2003.

PERALTA, A. J.; OSUNA, T. Diccionario Guaraní-Español y Español-Guaraní. Buenos Aires: Editorial Tupã, 1950.

PEREIRA, M. F. A. A. O falar de Soajo. 429 f. Dissertação (Licenciatura em Letras). Universidade de Lisboa, Lisboa, 1970.

PEREIRA DA COSTA, F. A. Vocabulário pernambucano. Recife: Imprensa Official, 1937.

PESSARAKI, M. Handbook of Cucurbits. Boca Raton: CRC Press US, 2016.

PFEIFER, W.; BRAUN, W. Etymologisches Wörterbuch des Deutschen A-L. Berlin: Akademie, 1993.

PIGNATTI, S. Flora d'Italia. Volume secondo. 1. ed. Bologna: Edagricole, 1982.

PIRES CABRAL, A. M. Língua Charra: Regionalismos de Trás-os-Montes e Alto Douro. Vol II: FZ. Lisboa: Âncora, 2013.

PORTO Alegre, A. J. G. Popularium Sul-Rio-Grandense (estudo de filologia e folclore). Porto Alegre: Ed. da UFRGS; Inst. Estadual do Livro, 1980.

POULLET, H. et al. Dictionnaire des expressions du créole guadeloupéen. Fort-de-France: Hatier-Martinique, 1984.

RADTKE, E.; THUN, H. Neue Wege der romanischen Geolinguistik. Eine Bilanz. In: RADTKE, E.;

Real Academia Española (RAE): Diccionario de la lengua española. 23. ed., [versión 23.3 en línea]. Disponível em: https://dle.rae.es. Acesso em: 05 abr. 2020.

ROCCA, L. D. Açorianos no Rio Grande do Sul: antecedentes e formação do espaço urbano do século XVIII. 2009. 657 f. Tese (Doutorado em Planejamento Urbano e Regional), UFRGS, Porto Alegre, 2009.

ROCHA, F. Nomes vulgares de plantas existentes em Portugal. Lisboa: DGEPC, 1996.

ROMAGUERA CORRÊA, J. et al. Vocabulário Sul-Rio-Grandense. Rio de Janeiro: Ed. Globo, 1964.

SAMPAIO, M. A. Vocabulário guarani-português. Porto Alegre: L\&PM, 1986.

SARAMAGO, J. et al. Atlas Linguístico-Etnográfico dos Açores (ALEAç). 2002. Disponível em: http://www.culturacores.azores.gov.pt/alea/. Acesso em: 10 abr. 2020.

SAUERHOFF, F. Etymologisches Wörterbuch der Pflanzennamen. Stuttgart: W. V., 2003.

SERAINE, F. Dicionário de termos populares registrados no Ceará. Rio de Janeiro: Simões, 1958. 
SIMÃO, T. Dicionário do falar raiano de Marvão. 1. ed. Lisboa: Ed. Colibri, 2016.

STAUB, A. O empréstimo linguístico: um estudo de caso. Porto Alegre: Letras de Hoje, 1983.

TAVARES DE BARROS, F. H. Topodinámica del Hunsrückisch: Cartografía y ejemplos del proceso de cambio y manutención del léxico en contexto de migración. 2019. 309 f. Tese (Doutorado em Estudos Linguísticos) - FB 10, Universidade de Bremen, UB, Bremen Alemanha, 2019.

THUN, H.; FORTE, C. E.; ELIZAINCÍN, A. El Atlas lingüístico Diatópico y Diastrático del Uruguay (ADDU): presentación de un proyecto. Iberoromania, Berlin, De Gruyter, n. 30, p. 26-62, 1989. https://doi.org/10.1515/iber.1989.1989.30.26

RADTKE, E.; THUN, H. Neue Wege der romanischen Geolinguistik. Eine Bilanz. In: RADTKE, E.; THUN, H. (Org.). Neue Wege der romanischen Geolinguistik: Akten des Symposiums zur Empirischen Dialektologie. Kiel: Westensee, 1996, p. 1-24.

THUN, H. La geolingüística como lingüística variacional general (con ejemplos del Atlas lingüístico Diatópico y Diastrático del Uruguay). In: RUFFINO, G. (Org.). International Congresso of Romance Linguistics and Philology (21.: Palermo: 1995). Tübingen, Niemeyer, v. 5, 1998. p. 701-729, 787-789. https://doi.org/10.1515/9783110934038.701

THUN, H. Altes und Neues in der Sprachgeographie. In: DIETRICH, W.; HOINKES, U. Romanistica se movet. Münster: NOdus-Publ, 2000. p. 69-89.

THUN, H. Pluridimensional Cartography. In: LAMELI, A. et al. Language and space: language mapping: an inter. handbook of linguistic variation. Berlin: De Gruyter, 2010. p. 506-523. https://doi.org/10.1515/9783110219166.1.506

TOKARSKI, F. Dicionário de regionalismos do sertão do Contestado. Florianópolis: Letras Contemporâneas, 2004.

TONIOLO, E. Vocabulário de Tibagi. Apucarana: FECEA, 1981. Disponível em: TLPGP. http://ilg.usc.gal/tesouro/pt/search\#search=normal\&mode=lema\&q=ab\%C3\%B3bora-

menina. Acesso em: 08 abr. 2020.

VOLKWEIS, R. A presença portuguesa no processo de formação das cidades do Brasil Meridional: a questão da origem açoriana de Triunfo - RS. 2011. 144 f. Dissertação (Mestrado) Programa de Pós-graduação em Planejamento Urbano e Regional, UFRGS, Porto Alegre, 2011.

Wörterbuch der luxemburgischen Mundart. XV, 532, Luxemburg: M. Huss, 1906. Disponível em: http://engelmann.uni.lu:8080/portal/WBB2009/WLM//wbgui py?mainmode=. Acesso em: 04 abr. 2020.

Recebido em: 20/04/2020.

Aprovado em: 16/08/2020. 
Anexo A: Mapa 01 - documentação da forma lexical Bower

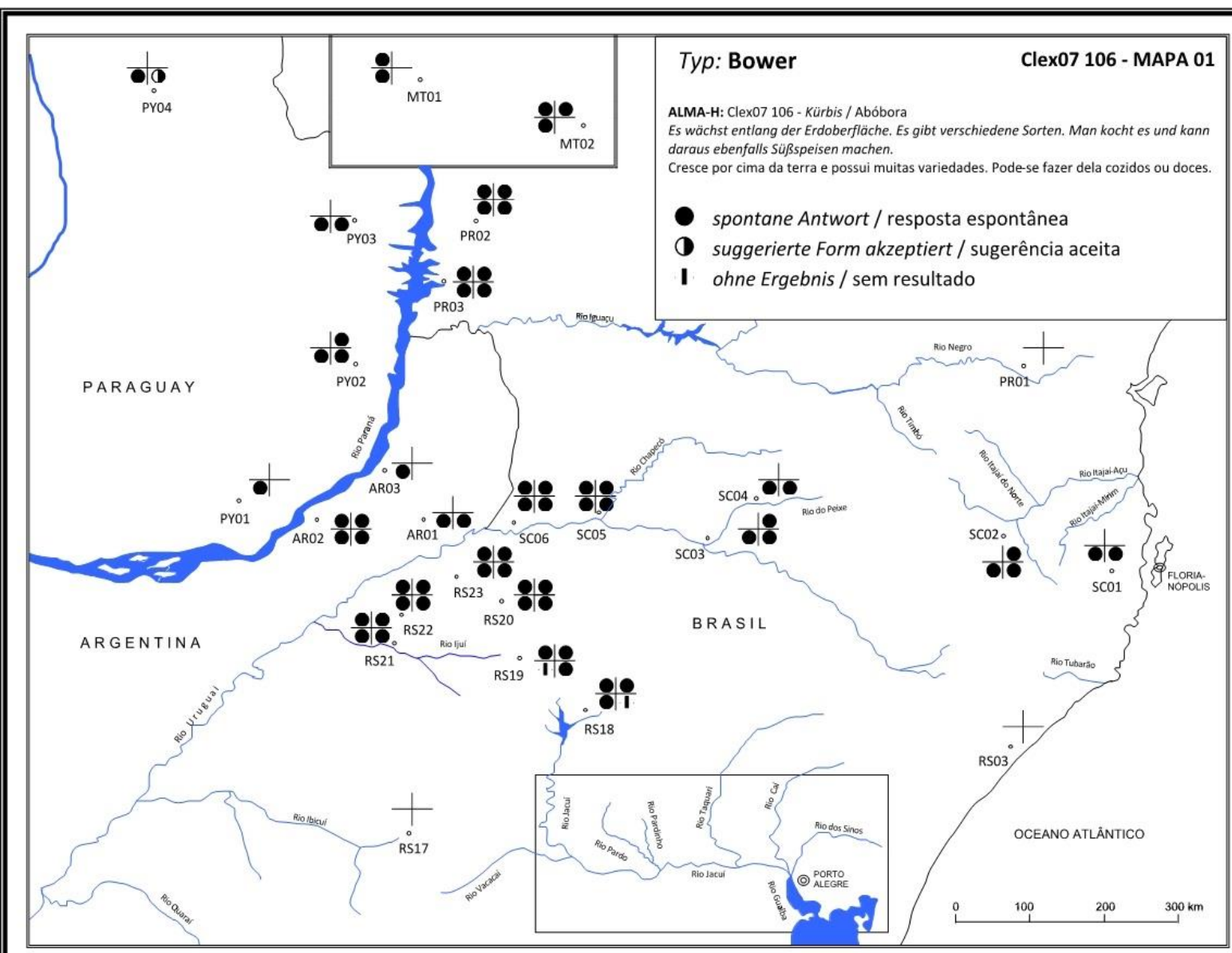

Atlas Linguístico-Contatual das Minorias Alemãs na Bacia do Prata: Hunsriqueano ALMA H Sprachkontaktatlas der deutschen Minderheiten im La Plata-Becken: Hunsrückisch

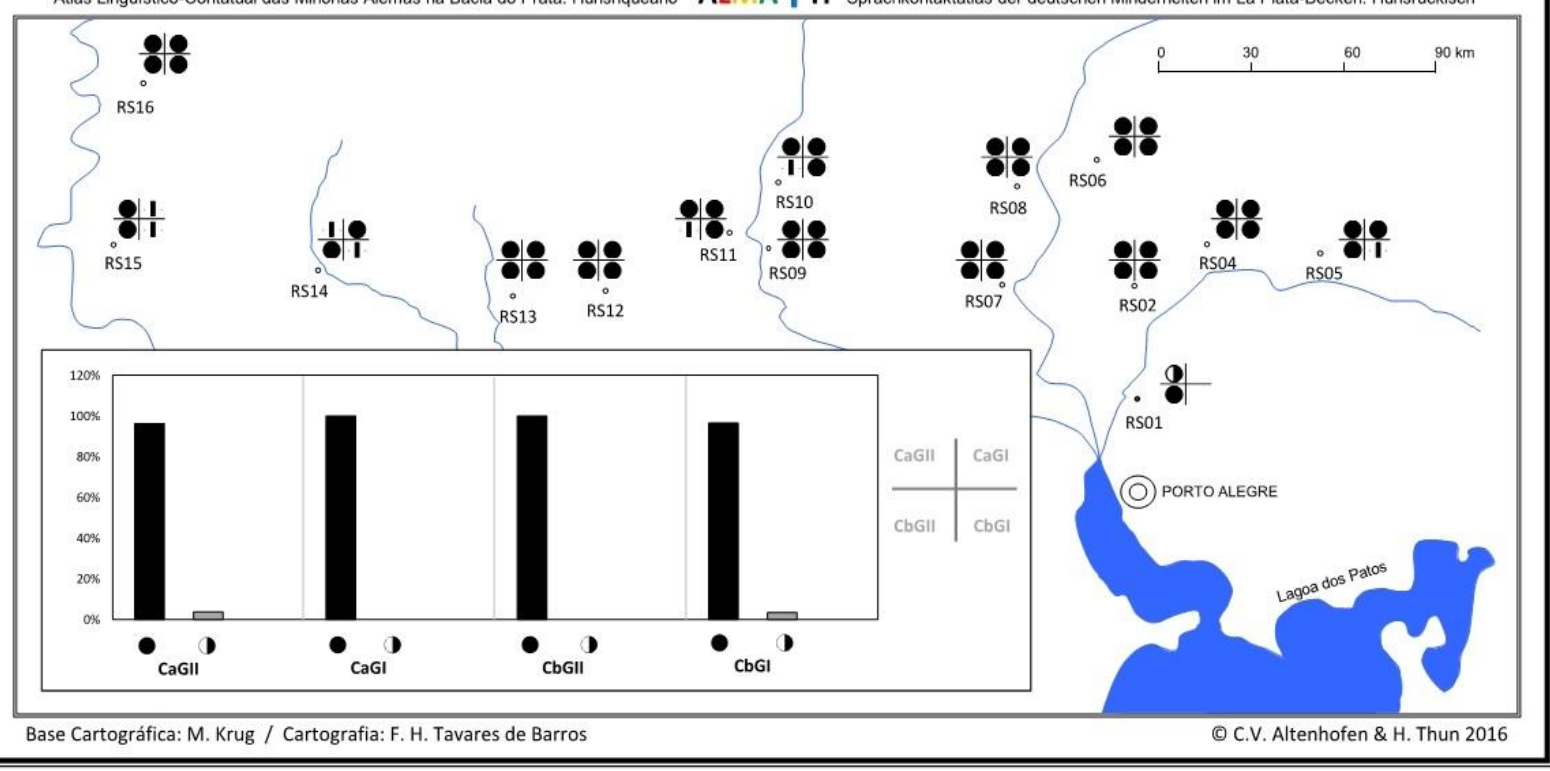


Anexo B: Mapa 02 - documentação das denominações para a C. maxima

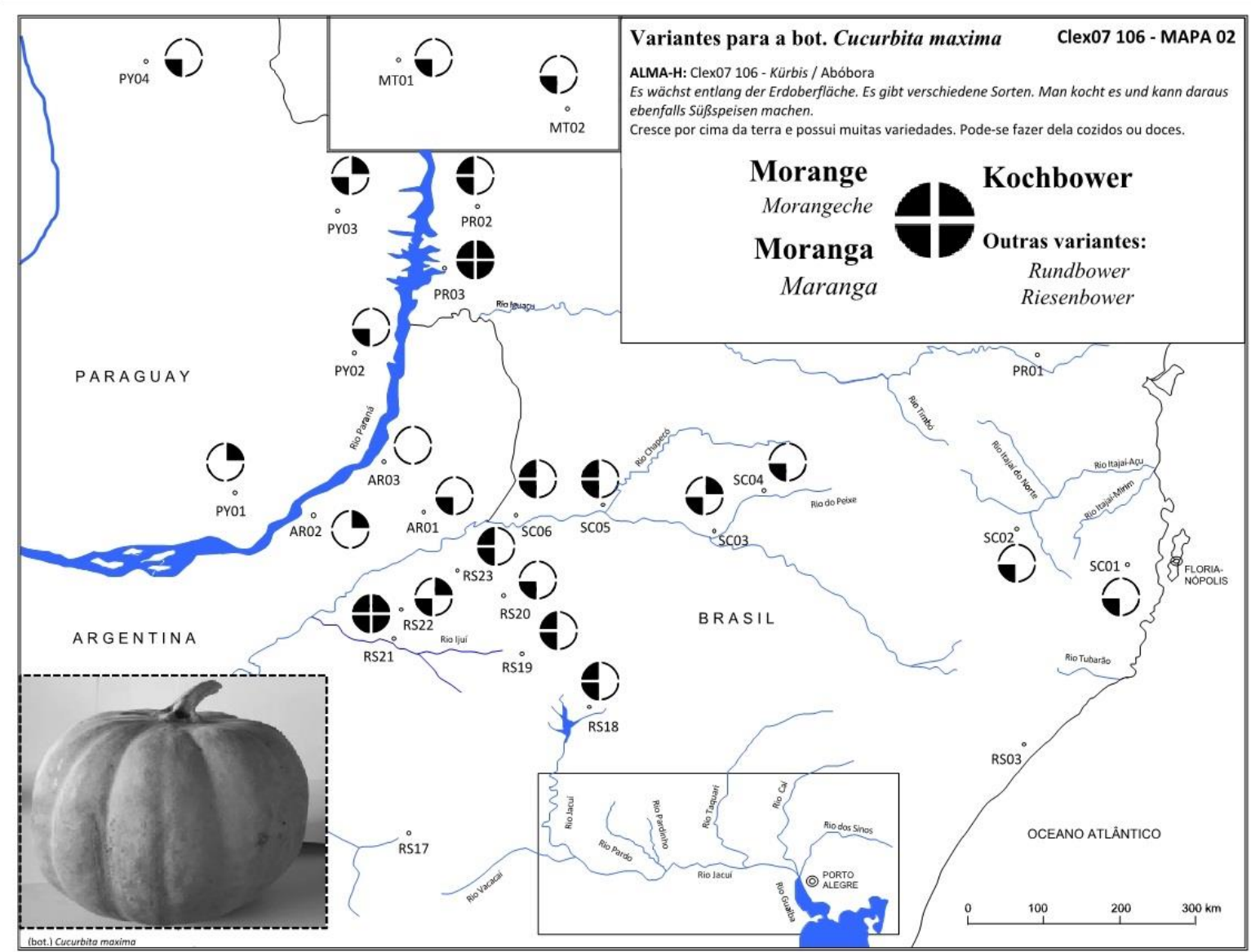

Atlas Linguistico-Contatual das Minorias Alemăs na Bacia do Prata: Hunsriqueano ALMA H Sprachkontaktatlas der deutschen Minderheiten im La Plata-Becken: Hunsrückisch

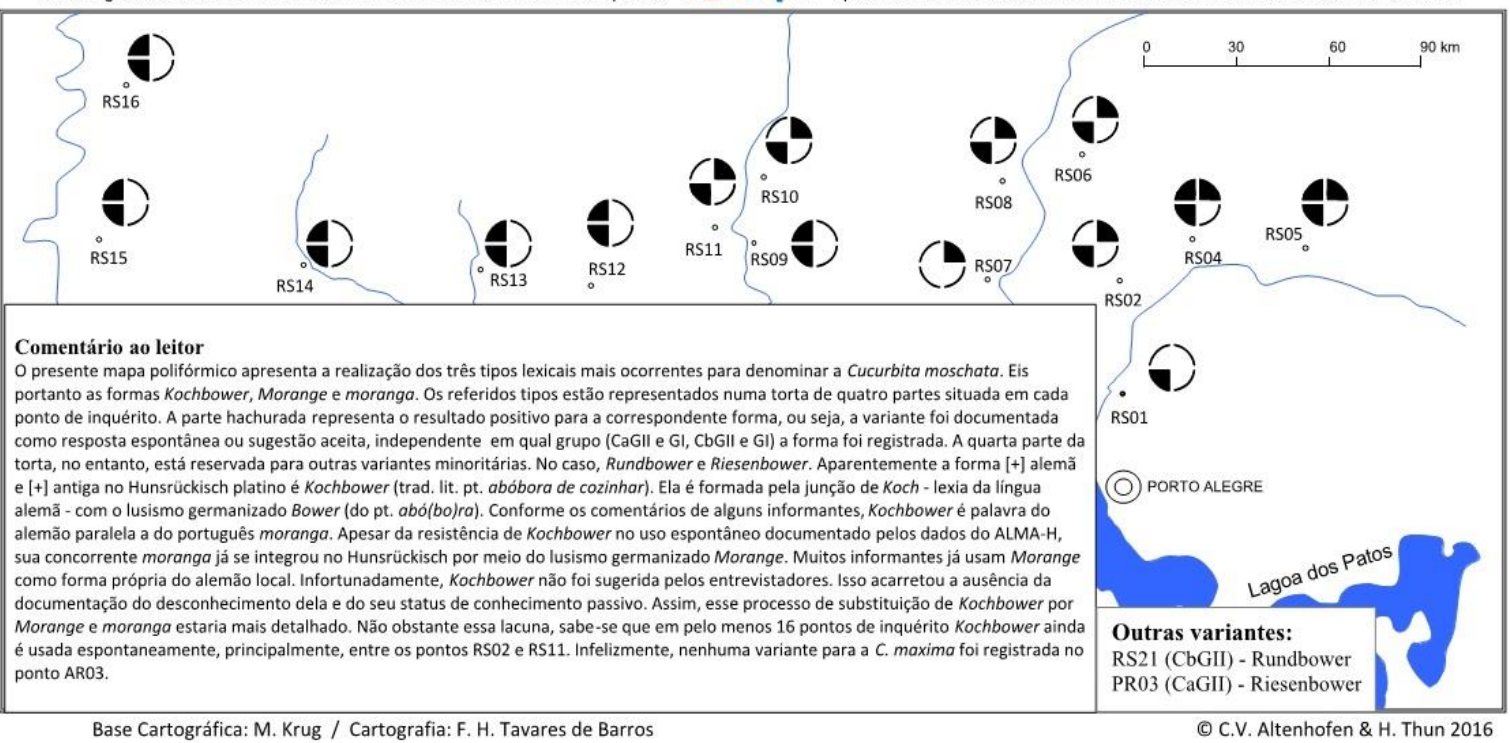


Anexo C: Mapa 03 - documentação das denominações para a C. moschata

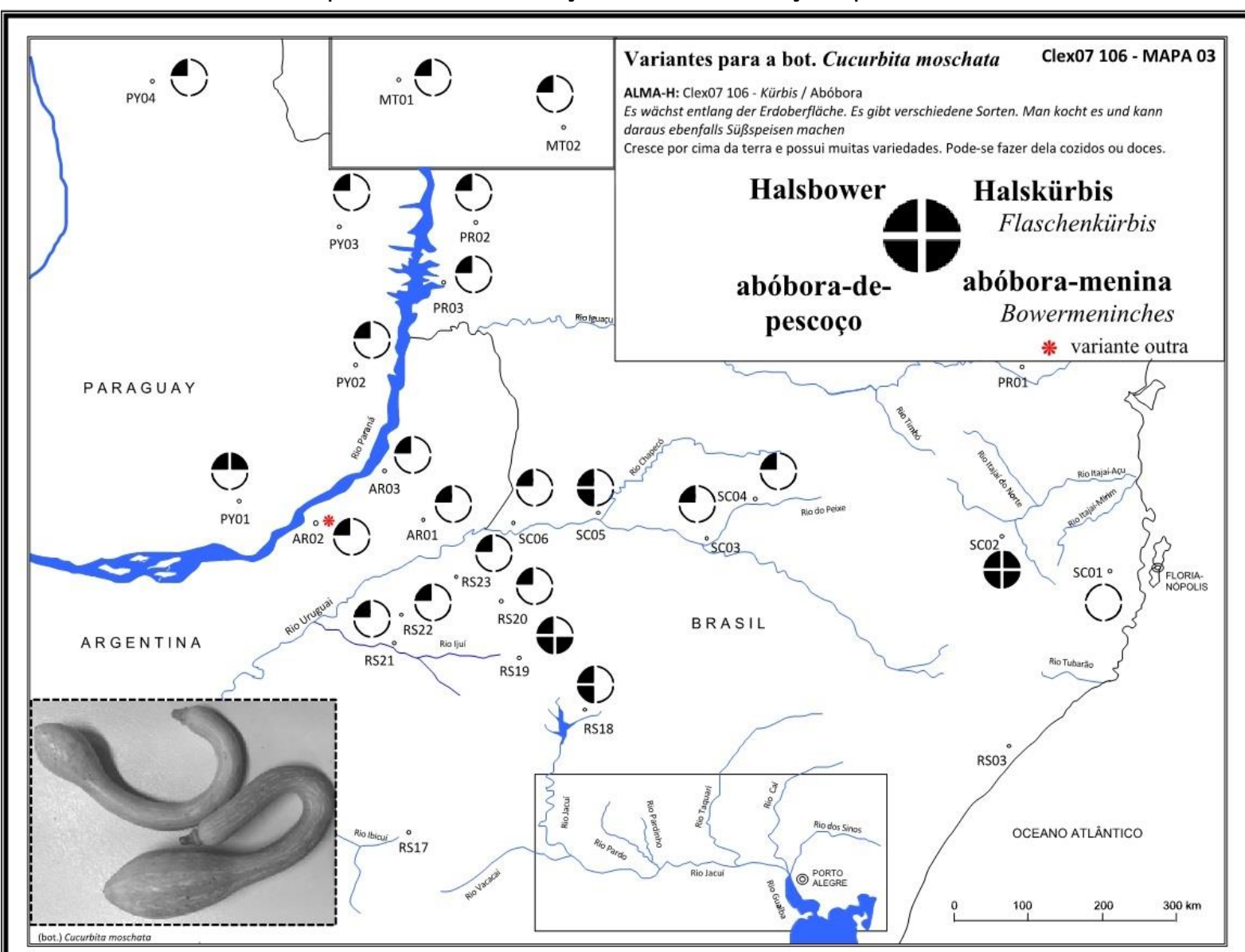

Atlas Linguístico-Contatual das Minorias Alemãs na Bacia do Prata: Hunsriqueano ALMA H Sprachkontaktatlas der deutschen Minderheiten im La Plata-Becken: Hunsrückisch

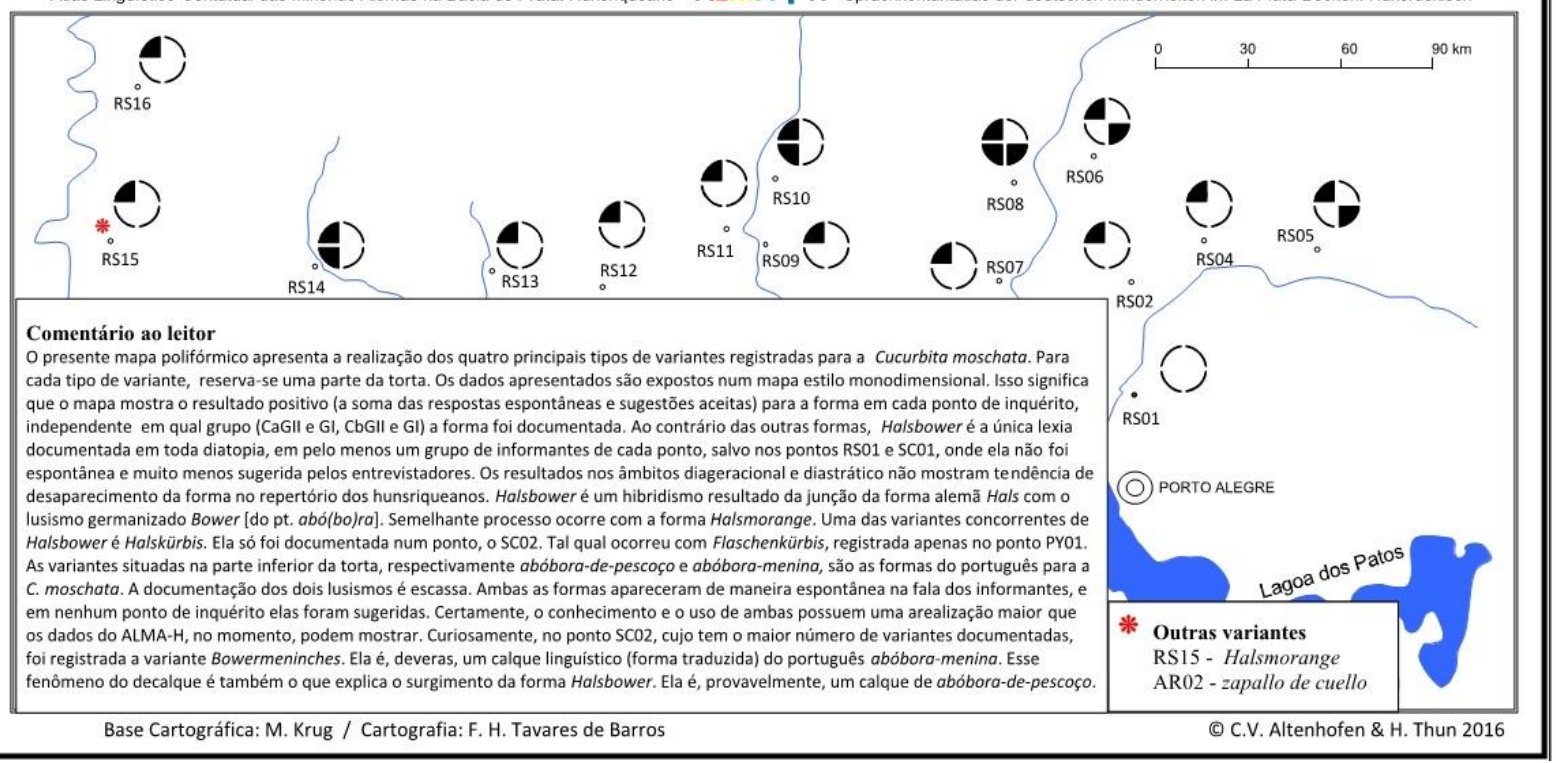

